\title{
Population pharmacokinetics of mefloquine, piperaquine and artemether-lumefantrine in Cambodian and Tanzanian malaria patients
}

\author{
Eva Maria Staehli Hodel ${ }^{1}$, Monia Guidi ${ }^{2,3}$, Boris Zanolari ${ }^{3}$, Thomas Mercier ${ }^{3}$, Socheat Duong ${ }^{4}$, \\ Abdunoor M Kabanywanyi ${ }^{5}$, Frédéric Ariey ${ }^{6}$, Thierry Buclin ${ }^{3}$, Hans-Peter Beck ${ }^{1}$, Laurent A Decosterd ${ }^{3}$, \\ Piero Olliaro ${ }^{7}$, Blaise Genton ${ }^{1,8^{*}+}$ and Chantal Csajka ${ }^{2,3^{*}+}$
}

\begin{abstract}
Background: Inter-individual variability in plasma concentration-time profiles might contribute to differences in anti-malarial treatment response. This study investigated the pharmacokinetics of three different forms of artemisinin combination therapy (ACT) in Tanzania and Cambodia to quantify and identify potential sources of variability.

Methods: Drug concentrations were measured in 143 patients in Tanzania (artemether, dihydroartemisinin, lumefantrine and desbutyl-lumefantrine), and in 63 (artesunate, dihydroartemisinin and mefloquine) and 60 (dihydroartemisinin and piperaquine) patients in Cambodia. Inter- and intra-individual variabilities in the pharmacokinetic parameters were assessed and the contribution of demographic and other covariates was quantified using a nonlinear mixed-effects modelling approach (NONMEM ${ }^{\circledR}$ ).
\end{abstract}

Results: A one-compartment model with first-order absorption from the gastrointestinal tract fitted the data for all drugs except piperaquine (two-compartment). Inter-individual variability in concentration exposure was about 40\% and $12 \%$ for mefloquine. From all the covariates tested, only body weight (for all antimalarials) and concomitant treatment (for artemether only) showed a significant influence on these drugs' pharmacokinetic profiles. Artesunate and dihydroartemisinin could not be studied in the Cambodian patients due to insufficient data-points. Modeled lumefantrine kinetics showed that the target day 7 concentrations may not be achieved in a substantial proportion of patients.

Conclusion: The marked variability in the disposition of different forms of ACT remained largely unexplained by the available covariates. Dosing on body weight appears justified. The concomitance of unregulated drug use (residual levels found on admission) and sub-optimal exposure (variability) could generate low plasma levels that contribute to selecting for drug-resistant parasites.

Keywords: Malaria, Population pharmacokinetics, Artemisinin-based combination therapy, Tanzania, Cambodia, Piperaquine, Mefloquine, Lumefantrine, Artemether, Nonlinear mixed-effects modelling

\footnotetext{
* Correspondence: blaise.genton@unibas.ch; chantal.csajka@chuv.ch

${ }^{\dagger}$ Equal contributors

'Swiss Tropical and Public Health Institute, University of Basel, Basel, Switzerland

${ }^{2}$ School of Pharmaceutical Sciences, University of Geneva, University of

Lausanne, Geneva, Switzerland

Full list of author information is available at the end of the article
} 


\section{Background}

Artemisinin-based combination therapy (ACT) is the current first-line treatment of malaria [1]. At present, the forms of ACT recommended by the World Health Organization (WHO) contain artemether (AM) plus lumefantrine (LF), artesunate (AS) plus either amodiaquine (AQ), mefloquine (MQ), pyronaridine (PN) or sulphadoxinepyrimethamine (SP), and dihydroartemisinin (DHA) plus piperaquine (PPQ) [1]. While hundreds of thousand courses of ACT are deployed each year [2], there is a limited number of studies measuring levels of drug exposure and relating it to treatment efficacy and safety.

Acquiring this information is paramount in order to optimize treatment and, especially, prevent resistance which may result from inadequate dosing. One of the main questions is to know if giving the recommended dose produces the same level of exposure in all, or otherwise what proportion or categories of subjects, and under which circumstances, would be systematically over- or under-dosed.

In other words, one needs to know if dosing regimens are adequate or if there are systematic dosing errors in which populations, especially on account of inter-subject variability and special groups like children and pregnant women. There is evidence that SP was systematically under-dosed in children and that the lower drug levels have contributed to the emergence of parasite resistance to this drug $[3,4]$. The situation is further complicated by the fact that the target doses and therapeutic windows have been established based mostly on data in adults, and assume all patients require the same level of exposure, while, for instance, the contribution of immunity to parasite clearance will change with age and malaria transmission.

In this respect, one will need to know how the pharmacokinetics contributes to efficacy or safety outcomes. Examples of proposed surrogate efficacy correlates are day 7 drug plasma concentrations for LF [5-7] and the time for drug plasma concentrations to fall below $500 \mu \mathrm{g} / \mathrm{l}$ (the minimal inhibitory concentration, MIC) for MQ [8].

Treating with a wrong dose may have both individual and general consequences. Over-exposure increases the risk of toxicity; under-dosing may lead to treatment failure, but also carries the risk of selecting for drugresistant parasites, which can spread to the rest of the population [9-12].

Two clinical trials found that AM-LF was highly efficacious in Tanzania, but much less effective (71\% cure rate) in Cambodia $[13,14]$. The cure rate in Cambodia increased to $86.5 \%$ in the subsequent years when $250 \mathrm{ml}$ milk and coconut biscuits were provided with each dose of the study medication to increase drug absorption [13]. These findings raised the question of the factors that could have contributed to the lower efficacy of AM-
LF in the Cambodian population. Parasite susceptibility is indeed a potential explanation [15-24], although no known molecular marker exists at the moment. Another possibility is that differences in drug levels induced by genetic or other factors could explain the difference in drug response between these two populations.

The objectives of this paper were to characterize the population pharmacokinetics of AS, DHA, MQ and PPQ in Cambodian patients and AM and LF in Tanzanian patients and to identify demographic and other factors that could explain variability in drug levels. In addition, day 7 concentrations have been shown to be a good surrogate marker of treatment success and model based-simulations of LF were performed to predict the proportion of patients with concentrations below the proposed day 7 cut-off values.

\section{Methods}

Study area, patients and data

Three studies have been conducted, one in Tanzania and two in Cambodia. The study profiles are described in Figure 1. The first study was performed during March to May 2008 at the Kibaoni Health Centre, Kilombero district, Morogoro region, Tanzania. A total of 1,672 patients with suspected malaria were screened by rapid diagnostic test (Paracheck, Orchid Biomedical Systems, India) and 389 (23\%) had parasitologically-proven Plasmodium falciparum malaria (confirmed and quantified by microscopy). After giving their informed consent to participate, patients were included in the study if they did not present signs of complicated malaria or any other severe concomitant illness. Six AM-LF (Coartem ${ }^{\bullet}$, Novartis Pharma, Switzerland) doses were administered at time $0,8,20,32,44$ and $56 \mathrm{~h}$ according to body weight (see Table 1); patients were either admitted for three days or asked to come back to the health facility for each drug administration. Mothers of breastfed patients were encouraged to feed their children and patients admitted were provided with food. Patients who reported that they have not eaten within two hours to prior dose intake were instructed to eat as soon as possible. Patients were seen by the clinical officer on days $0,1,2,3,7,14,28$, and 42 . A blood sample for pharmacokinetic measurement was taken at baseline (pre-dose on day 0 ) and on days 1, 2, and 7 at pre-defined random times after the last dosing. At each visit, a filter paper sample and a thin and thick smear were taken, in addition to axillary temperature, respiratory rate and haemoglobin measurements (only on days 0, 28 and 42) as well as evaluation of symptoms (e.g. headache, vomiting, and diarrhea). The exact dose and time of last drug intake, body weight, height, age, sex, food intake and concomitant medications were carefully recorded. If patients suffered from concomitant illnesses they 


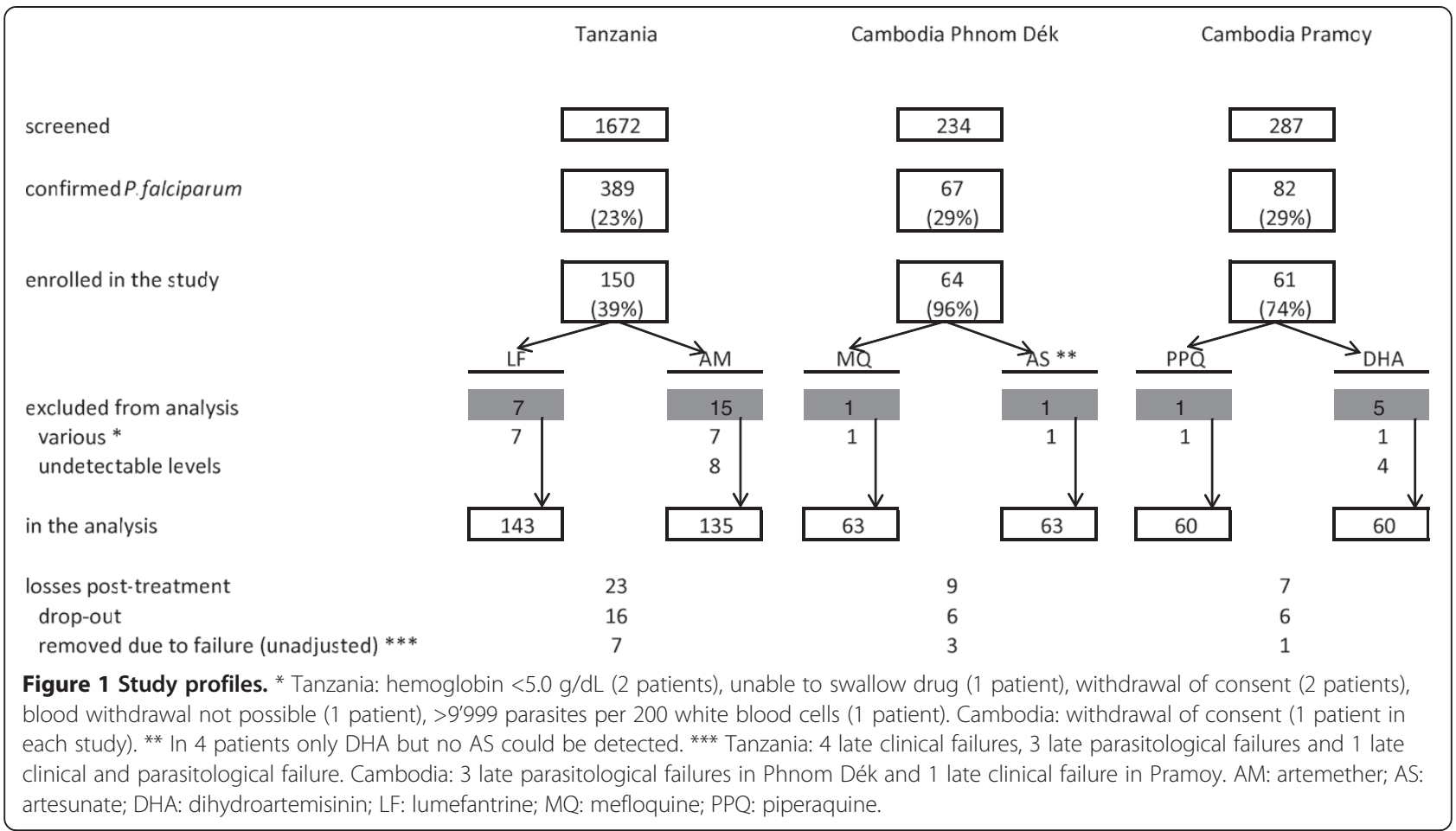

were provided with additional treatment (paracetamol, mebendazole, metronidazole, cloxacillin, amoxicillin).

The second study was conducted during October 2007 to February 2008 at the Phnom Dék Health Centre, Rovieng district, Preah Vihear province, Cambodia. Entry criteria and study procedures were identical as in the Tanzanian study with minor adaptations described below. In total, 234 suspected malaria cases were screened by microscopy, of whom 67 (29\%) were found to be infected with $P$. falciparum and 74 (32\%) with Plasmodium vivax (no mixed infections were detected). Pregnant or lactating women were excluded. Three doses of AS (Arsumax ${ }^{\oplus}$, Sanofi-Aventis, France) and MQ (Eloquine ${ }^{\bullet}$, Medochemie Ltd, Cyprus) were given according to body weight on three consecutive days (see Table 1). Patients were seen by the clinical officer on days 1, 2, 3, 7, 14, 21, 28, 35 and 42. Sampling for the pharmacokinetic study was done at predose and approximately $1 \mathrm{~h}$ after first dose intake on day 0 , and on days 1, 2, 7 and 14 at pre-defined random times after drug intake.

The third study was performed during July to October 2008 at Pramoy Health Centre, Veal Veng district, Pursat province, Cambodia. A total of 287 suspected malaria cases were screened by microscopy, of whom 82 (29\%) were infected with P. falciparum and 50 (17\%) with $P$. vivax (no mixed infections). Children younger than six years of age and pregnant or lactating women were excluded. Three doses of DHA-PPQ (Duo-Cotecxin ${ }^{\circ}$, Zhejiang Holley Nanhu Pharmaceutical Co., Ltd, China) were given according to age (as per national guidelines) on three consecutive days (see Table 1). Same follow-up and blood sampling as at Phnom Dék were performed.

\section{Laboratory methods}

Samples of $2 \mathrm{ml}$ of venous blood were collected on an EDTA Vacutainer and kept on ice for no longer than $6 \mathrm{~h}$ after withdrawal and then aliquoted into whole blood, plasma and pellet and immediately stored in liquid nitrogen or a $-80^{\circ} \mathrm{C}$ freezer. Plasma concentrations of 14 antimalarial drugs and their metabolites, i.e. AM, AS, DHA, amodiaquine, $N$-desethyl-amodiaquine, LF, desbutyllumefantrine (DLF), PPQ, PN, MQ, chloroquine, quinine and SP, were determined simultaneously using a liquid chromatography-tandem mass spectrometry method (LC-MS/MS) previously reported [25]. The method was validated according to FDA recommendations, including assessment of extraction yield, matrix effect variability, overall process efficiency, standard addition experiments as well as anti-malarials short- and longterm stability in plasma. The method is precise (interday coefficient of variation: $3.1-12.6 \%$ ) and sensitive (lower limits of quantification $0.15-3.0$ for basic/neutral anti-malarials and $0.75-5 \mathrm{ng} / \mathrm{ml}$ for artemisinin derivatives, respectively). The laboratory is part of the quality control system of the World-Wide Antimalarial Resistance Network (WWARN).

Pharmacogenetic profiles of the patients were generated using a sequencing strategy [26]. Detailed results of the population genetic analysis are presented elsewhere [27]. 
Table 1 Dosing regimens of the study drugs

\begin{tabular}{|c|c|c|c|c|c|}
\hline Drug & Body weight [kg] & Age [years] & Day 0 & Day 1 & Day 2 \\
\hline \multirow[t]{8}{*}{ AM-LF } & $5-14$ & & AM: $2 \times 20 \mathrm{mg}$ & AM: $2 \times 20 \mathrm{mg}$ & AM: $2 \times 20 \mathrm{mg}$ \\
\hline & & & LF: $2 \times 120 \mathrm{mg}$ & LF: $2 \times 120 \mathrm{mg}$ & LF: $2 \times 120 \mathrm{mg}$ \\
\hline & $15-24$ & & AM: $2 \times 40 \mathrm{mg}$ & AM: $2 \times 40 \mathrm{mg}$ & AM: $2 \times 40 \mathrm{mg}$ \\
\hline & & & LF: $2 \times 240 \mathrm{mg}$ & LF: $2 \times 240 \mathrm{mg}$ & LF: $2 \times 240 \mathrm{mg}$ \\
\hline & $25-34$ & & AM: $2 \times 60 \mathrm{mg}$ & AM: $2 \times 60 \mathrm{mg}$ & AM: $2 \times 60 \mathrm{mg}$ \\
\hline & & & LF: $2 \times 360 \mathrm{mg}$ & LF: $2 \times 360 \mathrm{mg}$ & LF: $2 \times 360 \mathrm{mg}$ \\
\hline & $\geq 35$ & & AM: $2 \times 80 \mathrm{mg}$ & AM: $2 \times 80 \mathrm{mg}$ & AM: $2 \times 80 \mathrm{mg}$ \\
\hline & & & LF: $2 \times 480 \mathrm{mg}$ & LF: $2 \times 480 \mathrm{mg}$ & LF: $2 \times 480 \mathrm{mg}$ \\
\hline \multirow[t]{6}{*}{ AS-MQ } & $10-12.5$ & & AS: $50 \mathrm{mg}$ & AS: $50 \mathrm{mg}$ & AS: $50 \mathrm{mg}$ \\
\hline & & & MQ: $125 \mathrm{mg}$ & MQ: $125 \mathrm{mg}$ & \\
\hline & $13-15.5$ & & AS: $50 \mathrm{mg}$ & AS: $50 \mathrm{mg}$ & AS: $50 \mathrm{mg}$ \\
\hline & & & MQ: $125 \mathrm{mg}$ & MQ: $125 \mathrm{mg}$ & MQ: $125 \mathrm{mg}$ \\
\hline & $16-24.5$ & & AS: $100 \mathrm{mg}$ & AS: $100 \mathrm{mg}$ & AS: 100 mg \\
\hline & & & MQ: $250 \mathrm{mg}$ & MQ: $250 \mathrm{mg}$ & \\
\hline \multirow[t]{4}{*}{+2} & $25-34.5$ & & AS: $150 \mathrm{mg}$ & AS: $150 \mathrm{mg}$ & AS: $150 \mathrm{mg}$ \\
\hline & & & MQ: $250 \mathrm{mg}$ & MQ: $250 \mathrm{mg}$ & MQ: $250 \mathrm{mg}$ \\
\hline & $35-37$ & & AS: $200 \mathrm{mg}$ & AS: $200 \mathrm{mg}$ & AS: 200 mg \\
\hline & & & MQ: $250 \mathrm{mg}$ & MQ: $250 \mathrm{mg}$ & MQ: $250 \mathrm{mg}$ \\
\hline & $38-57$ & & AS: $200 \mathrm{mg}$ & AS: $200 \mathrm{mg}$ & AS: 200 mg \\
\hline & & & MQ: $500 \mathrm{mg}$ & MQ: 500 mg & MQ: $250 \mathrm{mg}$ \\
\hline & $58-76$ & & AS: $200 \mathrm{mg}$ & AS: $200 \mathrm{mg}$ & AS: 200 mg \\
\hline & & & MQ: $500 \mathrm{mg}$ & MQ: $500 \mathrm{mg}$ & MQ: $500 \mathrm{mg}$ \\
\hline \multirow[t]{6}{*}{ DHA-PPQ } & & $6-11$ & DHA: $60 \mathrm{mg}$ & DHA: $60 \mathrm{mg}$ & DHA: 40 mg \\
\hline & & & PPQ: 480 mg & PPQ: 480 mg & PPQ: $320 \mathrm{mg}$ \\
\hline & & $11-16$ & DHA: $80 \mathrm{mg}$ & DHA: $80 \mathrm{mg}$ & DHA: $80 \mathrm{mg}$ \\
\hline & & & PPQ: 640 mg & PPQ: 640 mg & PPQ: $640 \mathrm{mg}$ \\
\hline & & $>16$ & DHA: 120 mg & DHA: 120 mg & DHA: 80 mg \\
\hline & & & PPQ: 960 mg & PPQ: 960 mg & PPQ: 640 mg \\
\hline
\end{tabular}

Abbreviations: $A M$ artemether, $A S$ artesunate, $D H A$ dihydroartemisinin, $L F$ lumefantrine, $M Q$ mefloquine, $P P Q$ piperaquine.

\section{Model-based pharmacokinetic analysis}

The pharmacokinetic analysis for each drug taken separately was performed using the NONMEM computer program [28] Version 6 (NM-TRAN version II). It uses mixed (fixed and random) effects regression to estimate population means and variances of the pharmacokinetic parameters and to identify factors that influence them.

\section{Structural model}

One-, two- and three-compartment pharmacokinetic models with first-order absorption, with and without absorption lag times, were compared. Additional one or two-compartments were used for anti-malarials presenting metabolite concentrations (AM and LF). The final parameters estimated were systemic clearance $(C L / F)$, inter-compartmental clearance $(Q / F)$, central volume of distribution $\left(V_{C} / F\right)$, peripheral volume of distribution
$\left(V_{P} / F\right)$ and absorption rate constant $\left(k_{\mathrm{a}}\right)$. Since no intravenous drug concentration data were available, these parameters represent apparent values. Where available, metabolite data were included into the model and metabolism rate constant from drug compartment to metabolite compartment $\left(k_{23}\right)$ and metabolite clearance $\left(C L_{\text {met }}\right)$ were also estimated. Owing to identifiability problems, the volume of distribution of the metabolites $\left(V_{M}\right)$ DLF and DHA were assumed to equal LF and AM $V_{C}$, respectively. Analysis of baseline plasma samples (i.e. day 0 prior treatment) showed that some patients had non-zero concentration of the drug, probably resulting from the treatment of the previous malaria episode or intake of non-declared drugs $[29,30]$. The observed baseline residual plasma concentrations were fitted by estimating a factor $\left(F_{0}\right)$ that provided an estimation of the residual doses from previous treatment. A schematic representation of the models is presented in Figure 2. 


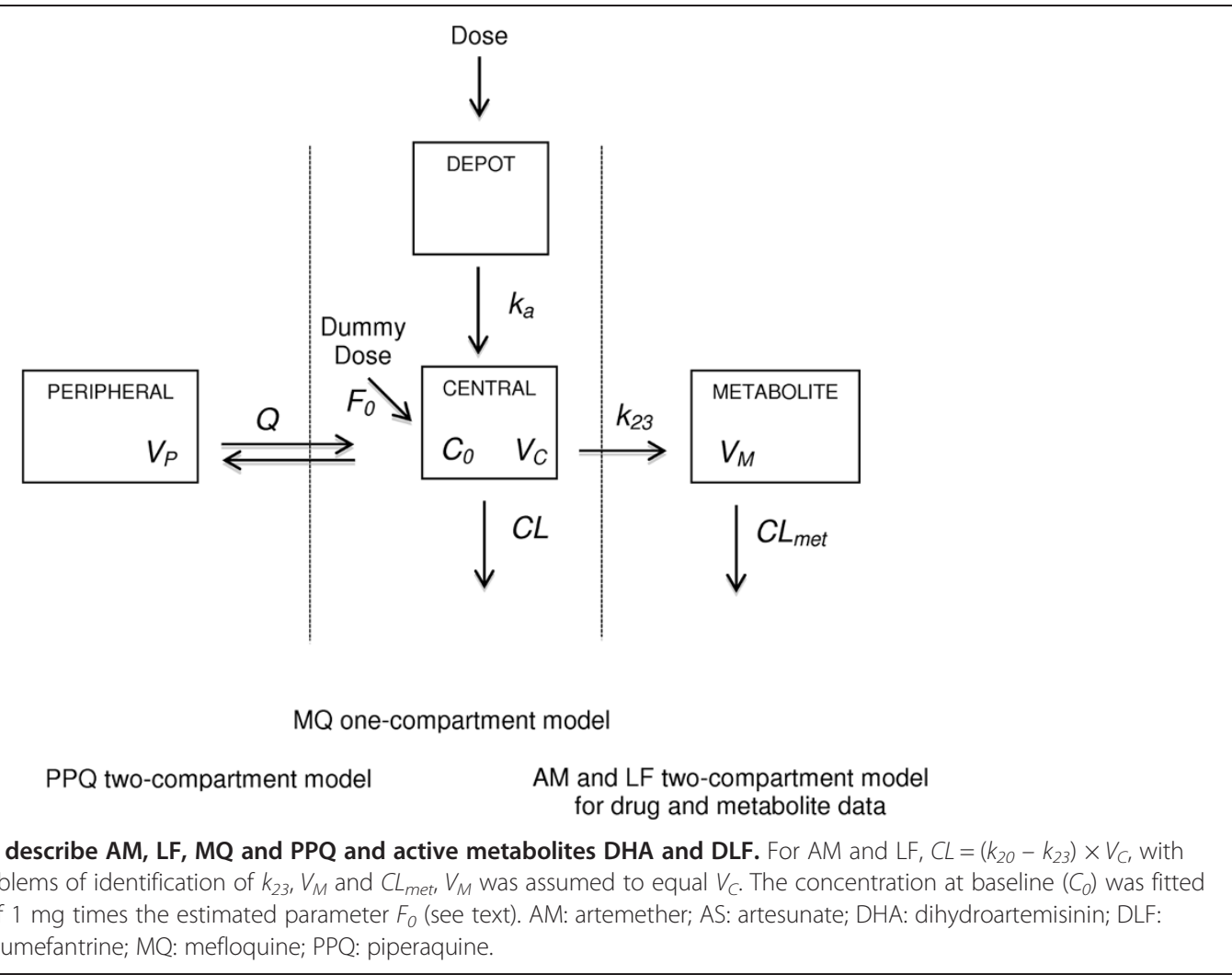

\section{Statistical model}

Exponential errors following a log-normal distribution were assumed for the description of inter-patient variability of the pharmacokinetic parameters and were of the form: $\theta_{i}=\theta \times e^{\eta_{j}}$ where $\theta_{i}$ is the individual pharmacokinetic parameter value in the $j^{\text {th }}$ individual, $\theta$ is the population parameter estimate, and $\eta_{j}$ is the random effect value, which is independently and normally distributed with a mean of 0 and variance $\omega^{2}$. Proportional and combined proportional-and-additive error models were compared to describe intra-patient (residual) variability for the mother compound, and if available for its metabolite using $C_{p i j}$ $\left(1+\varepsilon_{1 i j}\right)+\varepsilon_{2 i j}$ or $C_{m i j}\left(1+\varepsilon_{3 i j}\right)+\varepsilon_{4 i j}$, where $C_{p i j}$ are the corresponding predicted $i^{\text {th }}$ drug plasma concentration and $C_{m i j}$

Table 2 Concomitant medications included in the models

\begin{tabular}{|c|c|c|c|c|}
\hline Drug & Metabolism & Concomitant medications taken by study patients & Effect† & \%* \\
\hline \multirow[t]{5}{*}{ Artemether } & CYP2B6 $\neq[33,34]$ & & & $0 \%$ \\
\hline & CYP2C9 $\neq[33,34]$ & Ibuprofen, pyrimethamine and quinine & Strong to moderate inhibitor & $22 \%$ \\
\hline & CYP2C19: [34] & & & $0 \%$ \\
\hline & CYP3A4 [32-35] & $\begin{array}{l}\text { Caffeine, doxycycline, erythromycine and } \\
\text { metronidazole }\end{array}$ & Moderate inhibitors & $10 \%$ \\
\hline & CYP3A5 [32,34] & & & $0 \%$ \\
\hline Dihydroartemisinin & Glucuronidation [36] & - & & \\
\hline Lumefantrine & CYP3A4 [32,35] & $\begin{array}{l}\text { Caffeine, doxycycline, erythromycine and } \\
\text { metronidazole }\end{array}$ & Moderate inhibitors & $10 \%$ \\
\hline \multirow[t]{2}{*}{ Mefloquine } & CYP3A4 [37-39] & $\begin{array}{l}\text { Clarithromycine, caffeine, metronidazole } \\
\text { and tetracycline }\end{array}$ & Strong to moderate inhibitor & $8 \%$ \\
\hline & CYP3A5 [37] & & & $0 \%$ \\
\hline Piperaquine & Unknown [31] & Chloroquine, ibuprofen and quinine & $\begin{array}{l}\text { Strong to moderate inhibitor of } C Y P 2 C 8 \text {, } \\
\text { CYP2C9 } \\
\text { and / or CYP2D6 }\end{array}$ & $45 \%$ \\
\hline
\end{tabular}

* Percentage of patients in the study taking the respective inhibitor.

† From UpToDate Online 17.1 (http://www.uptodateonline.com/online/index.do).

₹ Only in vitro, not seen in healthy volunteers [40]. 
are the predicted metabolite concentration for the $j^{\text {th }}$ individual, and $\varepsilon_{1 i j}, \varepsilon_{2 i j}, \varepsilon_{3 i j}$, $\varepsilon_{4 i j}$, are independent normally distributed residual error terms with a mean of zero and a variance of $\sigma_{1}^{2}, \sigma_{2}^{2}, \sigma_{3}^{2}, \sigma_{4}^{2}$

\section{Covariate model}

Available covariates were body weight, height, age, sex, smoking status, pregnancy (for Tanzanians patients), and concomitant medications. Reported concomitant medications were coded as moderate to strong inhibitors or inducers of the cytochrome $\mathrm{P} 450$ isoenzymes (CYP) mostly involved in the metabolism of the anti-malarials (Table 2) [31-40]. This information was based on report of self-medication prior inclusion and prescription during the study.

The covariate analysis was performed using a stepwise insertion/deletion approach. Visual inspection of the correlation between post hoc individual estimates of the pharmacokinetic parameters and the available covariates was first conducted by graphical exploration. Potentially influential covariates were then incorporated sequentially into the pharmacokinetic model. The typical value of a given parameter $\theta$ (e.g., $C L$ ) was modeled to depend on the covariate $(X)$ either linearly $\theta=\theta_{a} \times\left[1+\theta_{b} \times X\right]$, exponentially $\theta=\theta_{a}^{X}$ or as an allometric power function $\theta=\theta_{a} \times X^{\theta_{b}}$, with $\theta_{a}$ representing the population value of the pharmacokinetic parameter and $\theta_{b}$ the contribution of the covariate $X$, centered on the mean value; categorical covariates were coded as 0 or 1 . In the allometric power models, $\theta_{b}$ was either estimated or fixed to literature values, i.e. 0.75 for $C L$ and 1 for $V_{C}$ [41]. At the end of the analysis, all patient characteristics showing an influence on the parameters were again confirmed by comparing the full model (with all factors included) to models from which each of the factors was removed sequentially.

\section{Model selection and parameter estimation}

NONMEM $^{\oplus}$ [28] (version 6.0, NM-TRAN, version II) was used with the FOCE INTERACTION method to fit the data. The difference in the minimum objective function value $(\triangle \mathrm{OFV})$ provided by $\mathrm{NONMEM}^{\oplus},(-2 \log$ likelihood, approximate $\chi^{2}$ distribution) was used to discriminate between models using the likelihood ratio test. A model was considered superior to another nested model when the OF value was reduced by at least 3.84 points $(p<0.05)$. Covariate analysis comprised forward selection of influential factors followed by backward deletion. Covariates were retained in the final model at the statistical level of $p<0.01$. Model assessment was based on diagnostic plots (goodness-of-fit plots) along with standard errors and correlation matrix of parameter estimates, size of residual errors and eta-shrinkage.

\section{Model validation}

The stability and the performance of the final population pharmacokinetic model were validated by the bootstrap method. Two hundred data sets were reconstructed by re-sampling from the original data using the Perl-speaks -NONMEM (PsN) Toolkit Version 3.2.4 [42,43]. The final population pharmacokinetic model was fitted repeatedly to the 200 bootstrapped samples and pharmacokinetic parameters were calculated for each dataset. The mean, standard error and 95\% confidence interval of each parameter obtained from the bootstrap analysis were then compared to the corresponding parameters obtained with the original dataset. The statistical analysis was performed using PsN version 3.2.4 [44]. The final model was also validated using visual predictive check (VPC) obtained by simulation of data for 1'000 individuals based on the final model and generating $2.5^{\text {th }}, 50^{\text {th }}$ and $97.5^{\text {th }}$ percentiles. The observed concentrations were plotted against the 95\% prediction interval (P.I.95\%) of the simulated dataset at each time point and visually compared. Figures were generated using GraphPad Prism (Version 4.00 for Windows, GraphPad Software, San Diego California USA [45]).

\section{Model-based simulations for lumefantrine}

Concentration-time profiles of lumefantrine in 1'000 individuals receiving two different 6-dose regimens over 3 days (doses at $0,8,20,32,44$ and $56 \mathrm{~h}$ ) and 5 days (doses at $0,8,24,48,72,96 \mathrm{~h}$ ) were performed based on the final model including inter-patient variability. These simulations served to purpose of quantifying the percentage of patients at day 7 below the different cut-off thresholds of $50 \mathrm{ng} / \mathrm{ml}, 175 \mathrm{ng} / \mathrm{ml}, 280 \mathrm{ng} / \mathrm{ml}$ and $600 \mathrm{ng} / \mathrm{ml}$ associated with treatment outcome [6]. In addition, the simulation-based predicted median time (95\% P.I.), estimated from time of last dose to $168 \mathrm{~h}$ (day 7), at which patients would exhibit concentrations below the cut-off values of $50 \mathrm{ng} / \mathrm{ml}, 175 \mathrm{ng} / \mathrm{ml}$ and $280 \mathrm{ng} / \mathrm{ml}$ was derived.

\section{Results}

\section{Population pharmacokinetic analyses}

Patients' baseline characteristics are summarized in Table 3. The median (range) of samples available per subject was 3 (2-4) for LF, 3 (1-4) for DLF, 2 (1-3) for AM and 2 (1-3) for DHA in Tanzania, 5 (3-6) for MQ, 1 for AS and 1 for DHA in Phnom Dék and 5 (4-6) for PPQ and 1 for DHA in Pramoy. The number of measured samples per time point is presented in Additional file 1.

\section{Artemether}

A one-compartment model with first-order absorption from the gastrointestinal tract adequately described the 
Table 3 Patients' characteristics at inclusion

\begin{tabular}{|c|c|c|}
\hline \multirow[b]{2}{*}{ Characteristic } & \multicolumn{2}{|c|}{ Kibaoni (Tanzania)* } \\
\hline & AM / DHAT & LF / DLF† \\
\hline Total patients & 135 & 143 \\
\hline Sex male / female (\%) & $56(41) / 79(59)$ & $62(43) / 81(57)$ \\
\hline Age median (range) [years] & $10(1-78)$ & $9(1-78)$ \\
\hline Body weight median (range) [kg] & $20(6.5-150)$ & $20(6.5-150)$ \\
\hline Height median (range) $[\mathrm{cm}]$ & $126(52-181)$ & $126(52-181)$ \\
\hline Pregnancy (\%) & $3(2)$ & $3(2)$ \\
\hline Smokers (\%) & $1(1)$ & $1(1)$ \\
\hline Median time sick (range) [days] & $3(1-14)$ & $3(1-14)$ \\
\hline Median body temperature (range) $\left[{ }^{\circ} \mathrm{C}\right]$ & $37.5(35.2-40.4)$ & $37.6(35.2-40.4)$ \\
\hline Median asexual parasites (range) $\left[\mu L^{-1}\right]$ & $15,360(120->399,960)^{a}$ & $15,360(120->399,960)^{a}$ \\
\hline Median respiratory rate (range) $\left[\mathrm{min}^{-1}\right]$ & $24(16-38)$ & $24(16-38)$ \\
\hline Median hematrocrit (range) [\%] & N.A. & N.A. \\
\hline \multirow[t]{2}{*}{ Median haemoglobin (range) $[\mathrm{g} / \mathrm{dL}]$} & $10.5(5.1-16.3)$ & $10.4(5.1-16.3)$ \\
\hline & \multicolumn{2}{|c|}{ Phnom Dék (Cambodia) } \\
\hline Characteristic & \multicolumn{2}{|c|}{ AS / DHAt and MQ } \\
\hline Total patients & \multicolumn{2}{|c|}{63} \\
\hline Sex male / female (\%) & \multicolumn{2}{|c|}{$37(59) / 26(41)$} \\
\hline Age median (range) [years] & \multicolumn{2}{|c|}{$18(2-57)$} \\
\hline Body weight median (range) [kg] & \multicolumn{2}{|c|}{$43(10.5-66)$} \\
\hline Height median (range) $[\mathrm{cm}]$ & \multicolumn{2}{|c|}{$153(73-172)$} \\
\hline Pregnancy (\%) & \multicolumn{2}{|c|}{ N.A. } \\
\hline Smokers (\%) & \multicolumn{2}{|c|}{$17(27)$} \\
\hline Median time sick (range) [days] & \multicolumn{2}{|c|}{$2(2-3)$} \\
\hline Median body temperature (range) $\left[{ }^{\circ} \mathrm{C}\right]$ & \multicolumn{2}{|c|}{$38.6(37.9-40.4)$} \\
\hline Median asexual parasites (range) $\left[\mathrm{LL}^{-1}\right]$ & \multicolumn{2}{|c|}{$19,600(1,200-160,000)$} \\
\hline Median respiratory rate (range) $\left[\mathrm{min}^{-1}\right]$ & \multicolumn{2}{|c|}{$28(20-38)$} \\
\hline Median hematrocrit (range) [\%] & \multicolumn{2}{|c|}{$30(24-37)$} \\
\hline \multirow[t]{2}{*}{ Median haemoglobin (range) [g/dL] } & \multicolumn{2}{|c|}{ N.A. } \\
\hline & \multicolumn{2}{|c|}{ Pramoy (Cambodia)* } \\
\hline Characteristic & DHA & PPQ \\
\hline Total patients & 56 & 60 \\
\hline Sex male / female (\%) & $34(61) / 22(39)$ & $38(63) / 22(37)$ \\
\hline Age median (range) [years] & $18(7-53)$ & $18(7-53)$ \\
\hline Body weight median (range) [kg] & $42(15-67)$ & $42(15-67)$ \\
\hline Height median (range) $[\mathrm{cm}]$ & $151(105-171)$ & $152(105-171)$ \\
\hline Pregnancy (\%) & N.A. & N.A. \\
\hline Smokers (\%) & $12(21)$ & $14(23)$ \\
\hline Median time sick (range) [days] & $2(1-3)$ & $2(1-3)$ \\
\hline Median body temperature (range) $\left[{ }^{\circ} \mathrm{C}\right]$ & $38.4(37.8-39.8)$ & $38.4(37.8-39.8)$ \\
\hline Median asexual parasites (range) $\left[\mu \mathrm{L}^{-1}\right]$ & $16,858(1038-219,333)$ & $17,229(1038-219,333)$ \\
\hline Median respiratory rate (range) $\left[\mathrm{min}^{-1}\right]$ & $28(20-40)$ & $28(20-40)$ \\
\hline Median hematrocrit (range) [\%] & $41(30-50)$ & $41(30-50)$ \\
\hline Median haemoglobin (range) [g/dL] & N.A. & N.A. \\
\hline
\end{tabular}

Abbreviations: $A M$ artemether, $A S$ artesunate, $D H A$ dihydroartemisinin, $L F$ lumefantrine, $M Q$ mefloquine, $P P Q$ piperaquine.

* The number of patients included for the final analysis was not equal for the artemisinin-derivative and the partner drug.

† Parent drug / metabolite.

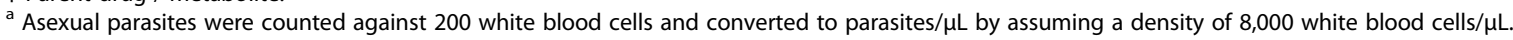


data; no improvement was obtained with a twocompartment model (difference in the objective function $(\triangle \mathrm{OFV})=0)$. For this drug, no baseline residual plasma concentrations were measured. In addition to $C L$, the assignment of an inter-patient variability on $k_{\mathrm{a}}$ (but on no other parameter) significantly improved the description of the data $(\triangle \mathrm{OFV}=-63)$. Univariate analyses showed that body weight $(\Delta \mathrm{OFV} \leq-45.1)$, age $(\Delta \mathrm{OFV} \leq-49.0)$, height $(\triangle \mathrm{OFV} \leq-42.7)$ and $\operatorname{sex}(\triangle \mathrm{OFV} \leq-13.3)$ significantly influenced $C L$. In multivariate analyses, only body weight remained significant since all other variables were correlated to body weight. Linear and allometric power functions described the effect of body weight on $C L$ similarly well (no statistical difference was observed between the two models $(\triangle \mathrm{OFV}=-2)$ ); the latter was finally chosen based on goodness of fit plots. The exponent of the allometric power function was estimated to be 0.66 and finally fixed to the literature value $(0.75)$, since statistically not different $(\triangle \mathrm{OFV}=1)$. Inhibitors of $C Y P 2 C 9$ and/or $C Y P 3 A 4$ significantly influenced $C L$ as well $(\triangle \mathrm{OFV}=-7)$, indicating a $70 \%$ decrease in $C L$ in patients exposed to either a $C Y P 2 C 9$ or $C Y P 3 A 4$ inhibitor. Multivariate analysis showed an additive influence of body weight and CYP inhibitors on $\mathrm{CL}(\triangle \mathrm{OFV}=-61$ relative to the model without covariates).

Metabolite concentrations (DHA) were included in the model using an additional compartment, assuming linear metabolism and elimination. The assignment of an inter-patient variability on the metabolism rate constant $k_{23}$ yielded a better fit of the data $(\Delta \mathrm{OFV}=-81)$, while no improvement was observed when assigning variability to the metabolite clearance $C L_{\text {met }}(\Delta \mathrm{OFV}=0)$. Finally, none of the available covariates significantly affected DHA pharmacokinetics. A proportional error model for drug and metabolite provided the best description of intra-patient variability. The parameter estimates for the final model and derived parameters are in Table 4. The concentration-time plots of AM and DHA in the 135 patients included in the analysis with average population predictions and 95\% prediction intervals is presented in Figure 3.

\section{Lumefantrine}

A one-compartment model with first-order absorption from the gastrointestinal tract and linear metabolism into DLF described adequately the data; a two-compartment model for LF or for DLF did not improve the model fit $(\triangle \mathrm{OFV}=0)$. The average estimated residual dose from previous treatments $\left(F_{0}\right)$ was $1.6 \mathrm{mg}$, which corresponds to $0.3-1.3 \%$ of the recommended LF first dose $(120-480 \mathrm{mg})$. Adding an inter-patient variability on $V_{C}(\Delta \mathrm{OFV}=-75)$, $k_{23}(\triangle \mathrm{OFV}=-199)$ and $F_{0}(\triangle \mathrm{OFV}=-17)$ in addition to $C L$ improved the description of the data, but no variability on the other parameters was significant. A proportional error model best described the residual intra-patient variability for LF and an additive one for DLF. Inclusion of age, height and body weight on both $C L$ and $V_{C}$ improved the fit $(\triangle \mathrm{OFV} \leq-30)$. Since age, height and body weight were correlated, only body weight was retained for further testing. Linear and allometric power functions adequately described its influence on $C L$ and $V_{C}$ equally well $(\triangle \mathrm{OFV} \leq-34)$; the latter was selected based on visual inspection of graphical analysis. The estimations of the exponents of the allometric power functions were 0.52 and 0.35 for $C L$ and $V_{C}$, respectively, and provided a better fit than the fixed literature values $(\triangle \mathrm{OFV} \leq-17)$. Sex, smoking status, pregnancy and concomitant medications did not affect $C L$ or $V_{C}(\triangle \mathrm{OFV} \geq-0.2)$. The parameter estimates for the final model and derived parameters are given in Table 4 . Figure 4 shows the concentrationtime plots of LF and DLF in the 143 patients included in the analysis with average population predictions and 95\% prediction intervals.

\section{Mefloquine}

A one-compartment model with first-order absorption from the gastrointestinal tract appropriately described the data, with no improvement using a two-compartment model $(\triangle \mathrm{OFV}=0)$. For this drug, the residual dose from previous treatments $\left(F_{0}\right)$ was estimated to be $33.1 \mathrm{mg}$, corresponding to $6.7-26.7 \%$ of an initial dose of $125-500 \mathrm{mg}$. A better fit was obtained by assigning an inter-patient variability on $V_{C}(\triangle \mathrm{OFV}=-172)$ and $F_{0}(\Delta \mathrm{OFV}=-211)$ in addition to $C L$. The use of a proportional error model for the residual intra-patient variability fitted the data well. Again, inclusion of age, height, body weight and sex improved the fit in univariate analyses $(\triangle \mathrm{OFV} \leq-136)$. Plots of $C L$ and $V_{C}$ as a function of body weight suggested that an allometric power function, with exponent fixed to literature values, should be preferred to a linear relationship. The addition of smoking status and concomitant medications on $C L$ and $V_{C}$ did not improve the model significantly $(\triangle \mathrm{OFV} \geq-1.2)$. Multivariate analysis indicated that body weight remained the unique significant covariate on both $C L$ and $V_{C}$. The parameter estimates for the final model and derived parameters are given in Table 4. Figure 5 depicts the simulated plasma concentration-time plot of MQ in the 63 patients included in the analysis with average population predictions and $95 \%$ prediction intervals.

\section{Piperaquine}

A two-compartment model with first-order absorption from the gastrointestinal tract described the data better than a one-compartment model $(\triangle \mathrm{OFV}=-97)$, but no additional benefit was seen with a three-compartment model $(\triangle \mathrm{OFV}=0)$. The residual dose of PPQ was estimated to be $123 \mathrm{mg}$, which corresponds to $12.8-25.6 \%$ 
Table 4 Final population parameter estimates of artemether, lumefantrine, mefloquine and piperaquine and estimates from the bootstrap evaluation in 200 replicates

\begin{tabular}{|c|c|c|c|c|c|c|c|}
\hline \multicolumn{5}{|c|}{ Population analysis } & \multicolumn{3}{|c|}{ Bootstrap evaluation } \\
\hline Parameter & Estimate & S.E. $^{a}$ & $\mathrm{IIV}^{\mathrm{b}}$ & S.E. $^{c}$ & Mean of 200 & S.E. & $95 \%$ C.I. $^{d}$ \\
\hline \multicolumn{8}{|l|}{ Artemether } \\
\hline$\overline{C L}[\mathrm{~L} / \mathrm{h} / \mathrm{kg}]$ & $24.7 \times B W^{0.75}$ & $10 \%$ & $44 \%$ & $17 \%$ & $24.4 \times B W^{0.75}$ & $10 \%$ & $19-29$ \\
\hline$\theta_{I N H}$ & -0.3 & $45 \%$ & & & -0.27 & $60 \%$ & $0.5-1.1$ \\
\hline$V_{C}[\mathrm{~L} / \mathrm{kg}]$ & 129 & $20 \%$ & & & 133 & $26 \%$ & $88-232$ \\
\hline$\overline{V_{M}[L]}$ & Fixed to $V_{C}$ & & & & & & \\
\hline$k_{a}\left[h^{-1}\right]$ & 0.27 & $11 \%$ & $119 \%$ & $11 \%$ & 0.27 & $14 \%$ & $0.21-0.35$ \\
\hline$k_{23}\left[h^{-1}\right]$ & 5.86 & $21 \%$ & $68 \%$ & $9 \%$ & 5.83 & $25 \%$ & $3.6-9.7$ \\
\hline$C L_{\text {met }}[\mathrm{L} / \mathrm{h}]$ & 419 & $30 \%$ & & & 440 & $42 \%$ & 213-927 \\
\hline$\overline{\sigma_{C}(\mathrm{CV} \%)}$ & $74 \%$ & $9 \%^{c}$ & & & $73 \%$ & $11 \%^{c}$ & $59 \%-86 \%$ \\
\hline$\overline{\sigma_{M}(C V \%)}$ & $119 \%$ & $11 \%^{c}$ & & & $116 \%$ & $9 \%^{c}$ & $88 \%-149 \%$ \\
\hline \multicolumn{8}{|c|}{ Lumefantrine } \\
\hline$\overline{C L}[\mathrm{~L} / \mathrm{h} / \mathrm{kg}]$ & $0.84 \times \mathrm{BW}^{\theta_{B W C L}}$ & $28 \%$ & $38 \%$ & $14 \%$ & $0.87 \times \mathrm{BW}^{\theta_{B W C L}}$ & $24 \%$ & $0.51-1.37$ \\
\hline$\theta_{B W C L}$ & 0.52 & $19 \%$ & & & 0.51 & $14 \%$ & $0.36-0.65$ \\
\hline$V_{C}[\mathrm{~L} / \mathrm{kg}]$ & $59.9 \times \mathrm{BW}^{\theta_{\text {BWCL }}}$ & $28 \%$ & $33 \%$ & $11 \%$ & $59.5 \times \mathrm{BW}^{\theta_{\text {BwCL }}}$ & $24 \%$ & $35.1-91.9$ \\
\hline$\overline{\theta_{B W W C}}$ & 0.35 & $28 \%$ & & & 0.34 & $19 \%$ & $0.19-0.45$ \\
\hline$V_{M}[\mathrm{~L}]$ & Fixed to $V_{C}$ & & & & & & \\
\hline$k_{a}\left[h^{-1}\right]$ & 0.54 & $31 \%$ & & & 0.48 & $43 \%$ & $0.11-0.88$ \\
\hline$F_{0}[\mathrm{mg}]$ & 2.53 & $14 \%$ & $103 \%$ & $14 \%$ & 2.45 & $15 \%$ & $1.58-3.28$ \\
\hline$k_{23}\left[h^{-1}\right]$ & $3.7 \times 10^{-4}$ & $12 \%$ & $38 \%$ & $15 \%$ & $3.7 \times 10^{-4}$ & $9 \%$ & $(3.0-4.4) \times 10^{-4}$ \\
\hline$\overline{C L_{\text {met }}}[\mathrm{L} / \mathrm{h}]$ & 4.8 & $10 \%$ & & & 4.6 & $13 \%$ & $3.4-5.7$ \\
\hline$\overline{\sigma_{C}(\mathrm{CV} \%)}$ & $60 \%$ & $9 \%^{c}$ & & & $61 \%$ & $31 \%$ & $55 \%-77 \%$ \\
\hline$\overline{\sigma_{M}\left[\mu \mathrm{molL}^{-1}\right]}$ & 0.013 & $4 \%^{c}$ & & & 0.013 & $45 \%$ & $0.010-0.016$ \\
\hline \multicolumn{8}{|l|}{ Mefloquine } \\
\hline $\mathrm{CL}[\mathrm{L} / \mathrm{h} / \mathrm{kg}]$ & $0.10 \times B^{0.75}$ & $5 \%$ & $12 \%$ & $88 \%$ & $0.10 \times B W^{0.75}$ & $5 \%$ & $(0.09-0.11)$ \\
\hline$\underline{V_{C}[\mathrm{~L} / \mathrm{kg}]}$ & $8.93 \times B W$ & $6 \%$ & $19 \%$ & $96 \%$ & $9.01 \times B W$ & $6 \%$ & $(8.04-10.20)$ \\
\hline$k_{a}\left[h^{-1}\right]$ & 0.15 & $14 \%$ & & & 0.15 & $14 \%$ & $0.12-0.19$ \\
\hline$F_{0}[\mathrm{mg}]$ & 33.1 & $56 \%$ & $175 \%$ & $48 \%$ & 31.0 & $43 \%$ & $11.8-48.1$ \\
\hline$\sigma_{C}\left[\mu \mathrm{molL}^{-1}\right]$ & $43 \%$ & $6 \%^{c}$ & & & $43 \%$ & $6 \%^{c}$ & $0.14-0.22$ \\
\hline \multicolumn{8}{|l|}{ Piperaquine } \\
\hline$C L[\mathrm{~L} / \mathrm{h} / \mathrm{kg}]$ & $4.50 \times \mathrm{BW}^{0.75}$ & $13 \%$ & $45 \%$ & $61 \%$ & $4.26 \times \mathrm{BW}^{0.75}$ & $22 \%$ & $(3.24-5.76)$ \\
\hline$V_{C}[\mathrm{~L} / \mathrm{kg}]$ & $346 \times B W$ & $12 \%$ & $65 \%$ & $48 \%$ & $347 \times B W$ & $13 \%$ & $(260-432)$ \\
\hline$Q[\mathrm{~L} / \mathrm{h}]$ & 122 & $13 \%$ & & & 126 & $13 \%$ & $86-158$ \\
\hline$V_{p}[\mathrm{~L}]$ & 18,600 & $22 \%$ & $50 \%$ & $77 \%$ & 20,053 & $37 \%$ & $8,778-28,422$ \\
\hline$k_{a}\left[h^{-1}\right]$ & 0.93 & $28 \%$ & & & 1.00 & $34 \%$ & $0.35-1.52$ \\
\hline$F_{0}[\mathrm{mg}]$ & 123 & $18 \%$ & & & 125 & $18 \%$ & $75-171$ \\
\hline$\overline{\sigma_{C}\left[\mu \mathrm{molL}^{-1}\right]}$ & $41 \%$ & $10 \%^{c}$ & & & $41 \%$ & $6 \%^{c}$ & $0.14-0.21$ \\
\hline
\end{tabular}

Abbreviations: $C L$ clearance, $B W$ body weight, $\theta_{I N H}$ inhibitors effect (CYP3A4 and/or CYP2C19) on CL expressed as (1- $\left.\theta_{I N H} \times I N H\right), V_{C}$ central volume of distribution, $Q$ inter-compartment clearance, $V_{M}$ volume of distribution of the metabolite, $V_{P}$ peripheral volume of distribution, $k_{a}$ first-order absorption rate constant, $F_{0}$ residual amount from the previous treatment, $k_{23}$ metabolism rate constant, $C L_{\text {met }}$ metabolite clearance, $\sigma_{C}$ exponential residual error for the central compartment, $\sigma_{M}$ : exponential residual error for the metabolite compartment.

${ }^{a}$ Standard error (S.E.) of the estimate $\theta_{i}$ defined as S.E estimate/estimate, expressed as a percentage.

${ }^{b}$ Inter-individual variability.

c Standard error (S.E.) of the coefficient of variation defined as $\sqrt{ }$ S.E estimate/estimate, expressed as a percentage.

d $95 \%$ confidence interval (C.I.).

of an initial dose of 480-960 mg. Assigning an inter-patient variability on $V_{C}(\Delta \mathrm{OFV}=-129)$ and $V_{P}(\Delta \mathrm{OFV}=-17)$ in addition to $C L$ improved the fit and the use of a proportional error model for the residual intra-patient variability fitted the data adequately. $C L$ and $V_{C}$ were again influenced by body weight $(\triangle \mathrm{OFV}=-14$ and -27 , 


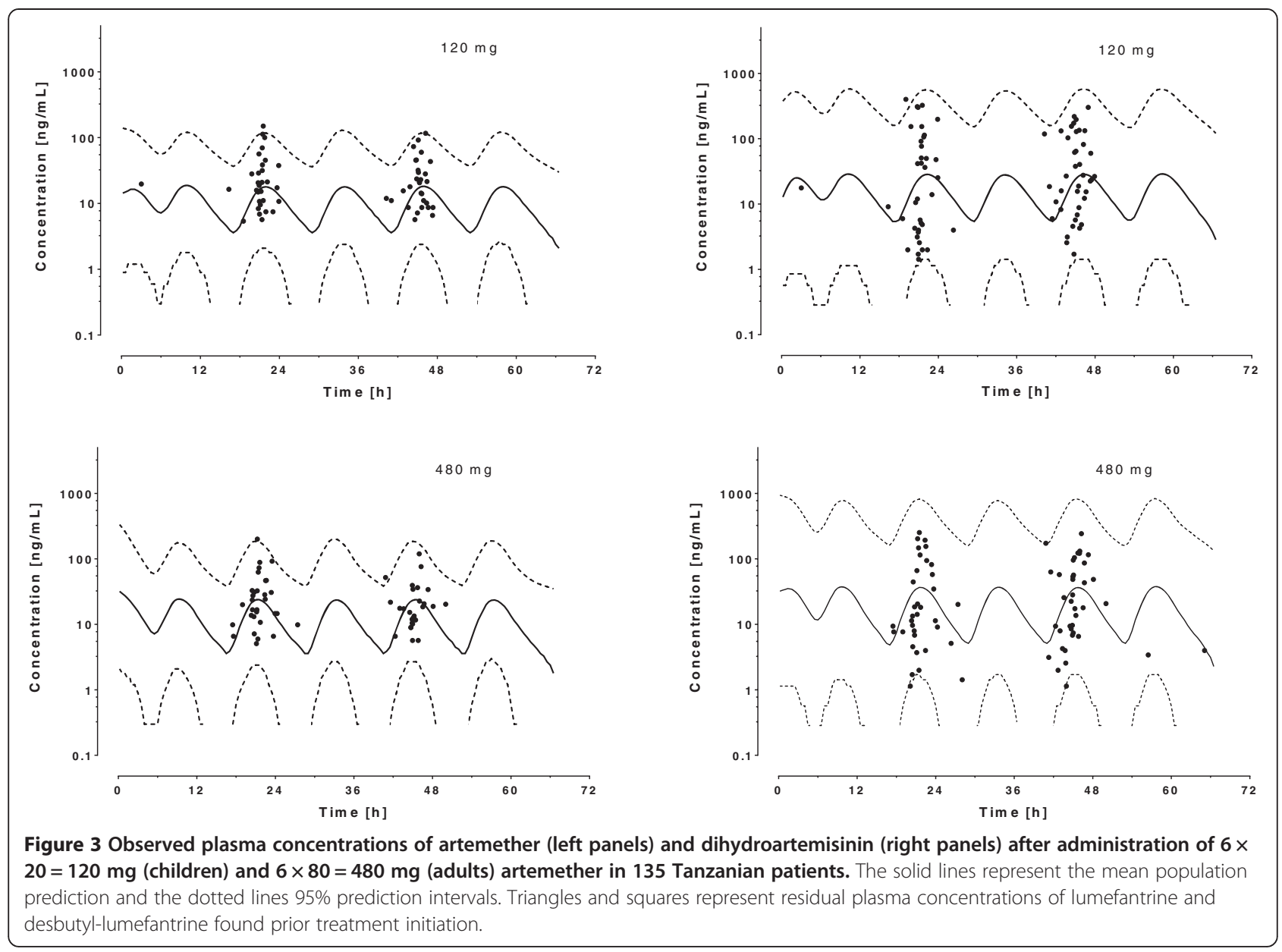

respectively); the relationship was best described using an allometric power function with exponents fixed to the literature values, and was not statistically different from estimated values $(\triangle \mathrm{OFV} \geq-2)$. Addition of sex or smoking status as covariates of $C L$ did not improve the model fit $(\triangle \mathrm{OFV} \geq-2)$. As the metabolizing CYP of PPQ are not known and few concomitant treatments were reported, this variable was not included in the model. The parameter estimates for the final model and derived parameters are given in Table 4. Figure 6 shows the simulated plasma concentration-time plot of PPQ in the 60 patients included in the analysis with average population predictions and $95 \%$ prediction intervals.

\section{Concentration-time simulations of lumefantrine}

The day 7 predicted median concentrations of lumefantrine after administration of a 6 dose-regimen over 3 days were $300.9 \mathrm{ng} / \mathrm{ml}$ (P.I.95\% 12.2-2015.0 ng/ml). Considering the large inter-patient variability in LF kinetics, $11 \%$ of the patients would exhibit day 7 concentrations below the cut-off of $50 \mathrm{ng} / \mathrm{ml}, 33 \%$ below $175 \mathrm{ng} / \mathrm{ml}, 48 \%$ below $280 \mathrm{ng} / \mathrm{ml}$ and $71 \%$ below $600 \mathrm{ng} / \mathrm{ml}$. Prolonging the time of drug administration over 5 days would provide median concentrations of $608.7 \mathrm{ng} / \mathrm{ml}$ (P.I.95\% $69.5-3515 \mathrm{ng} / \mathrm{ml}$ ), with $1 \%, 10 \%, 21 \%$ and $49 \%$ of patients with concentrations below the cut-off of $50 \mathrm{ng} / \mathrm{ml}$, $175 \mathrm{ng} / \mathrm{ml}, 280 \mathrm{ng} / \mathrm{ml}$ and $600 \mathrm{ng} / \mathrm{ml}$, respectively. In addition, simulations predicted that patients would exhibit concentrations below the cut-off values of $50 \mathrm{ng} / \mathrm{ml}$, $175 \mathrm{ng} / \mathrm{ml}$ and $280 \mathrm{ng} / \mathrm{ml}$ in a median (95\% P.I.) of 152 h (126.8-176.3 h), 142 h (108.7-175.3 h) 136 h (99.7-172.3 h), respectively after a standard dosing regimen of 6 doses over 3 days. Increasing the 6-dose regimen over 5 days would increase the median time to $160 \mathrm{~h}(147.2-173.4 \mathrm{~h})$, to $156 \mathrm{~h}(137.3-174.3 \mathrm{~h})$ and to $152 \mathrm{~h}(128.2-174.9 \mathrm{~h})$ for the 3 proposed cut-off values, respectively (Figure 7).

\section{Discussion}

This study describes the disposition of three widely used forms of ACT (namely; AM-LF, AS-MQ and DHA-PPQ) and explores factors potentially influencing the marked variability in drug exposure. The estimated values of clearance and volume of distribution for AM (including 


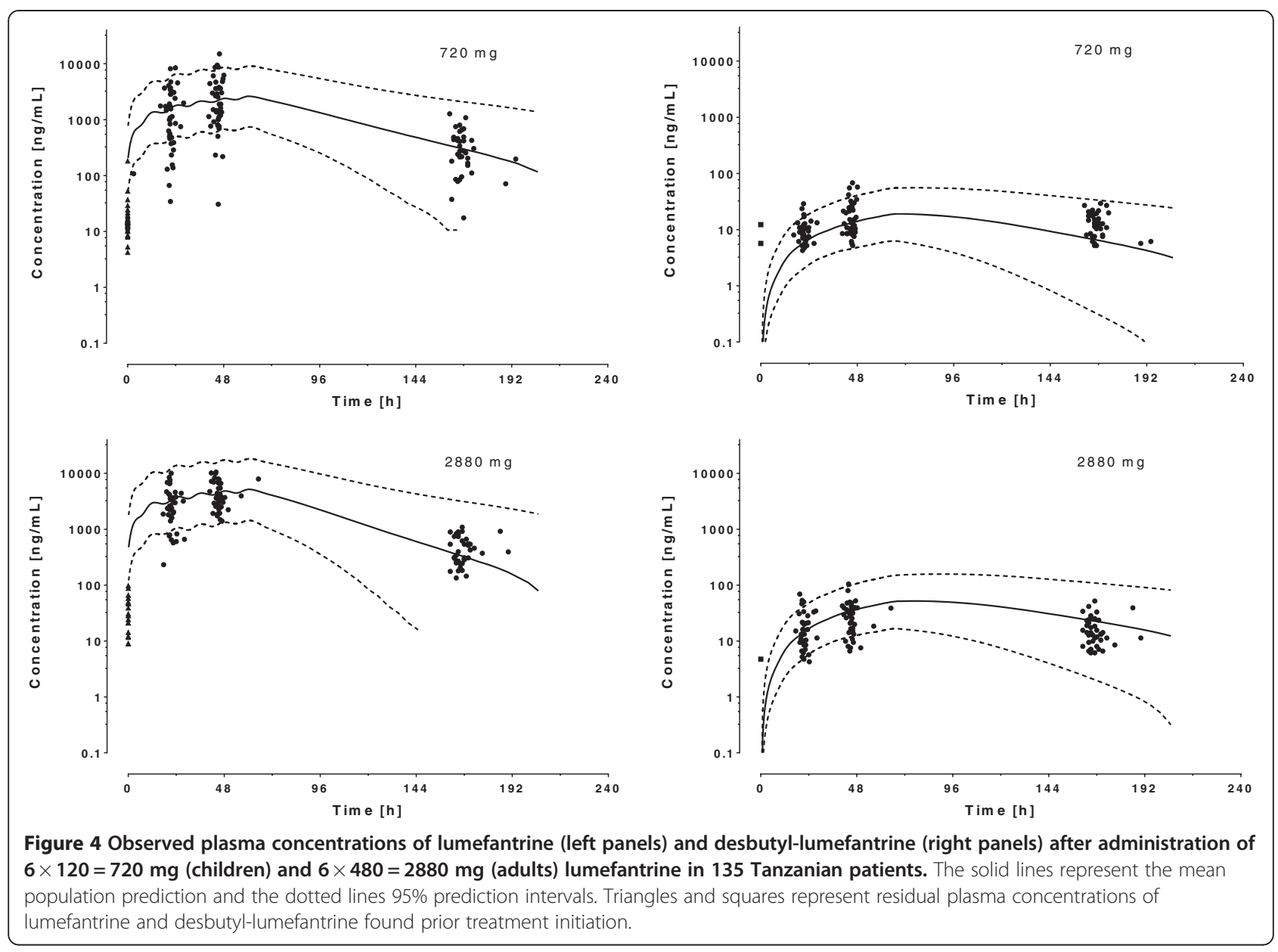

its metabolite DHA), LF (including its desbutyl metabolite DLF), MQ and PPQ are in line with previously published results (see Table 5 for review), so are the large inter-patient and marked intra-individual variability $[8,32$, 46-55]. Below some of the key findings are discussed.

\section{Prior treatments}

Interestingly and worryingly, more than half of the patients had residual concentrations above the lower limit of quantification of at least one antimalarial on admission $74.3 \%$ in Tanzania Kibaoni, $51.6 \%$ in Cambodia

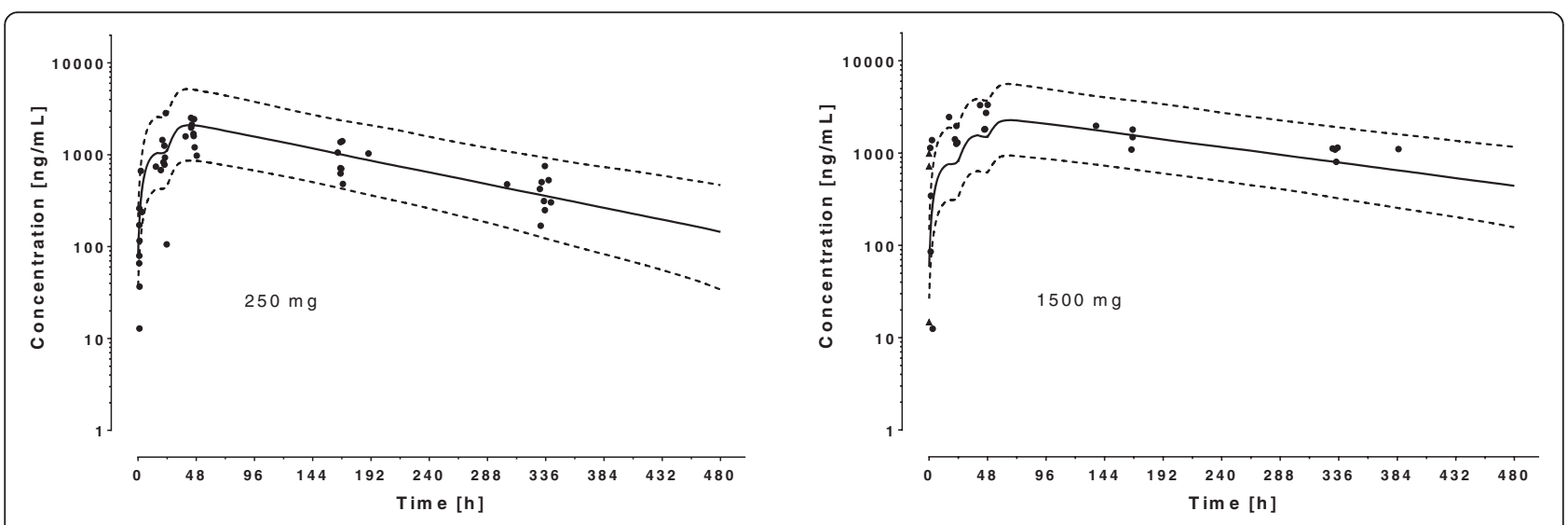

Figure 5 Observed mefloquine plasma concentration after administration of a $2 \times 125=250 \mathrm{mg}$ (children) and $3 \times 500=1500$ mg (adults) dose in 63 Cambodian patients. The solid lines represent the mean population prediction the dotted lines the 95\% prediction intervals. Triangles represent residual plasma concentrations of mefloquine or piperaquine found prior treatment initiation. 

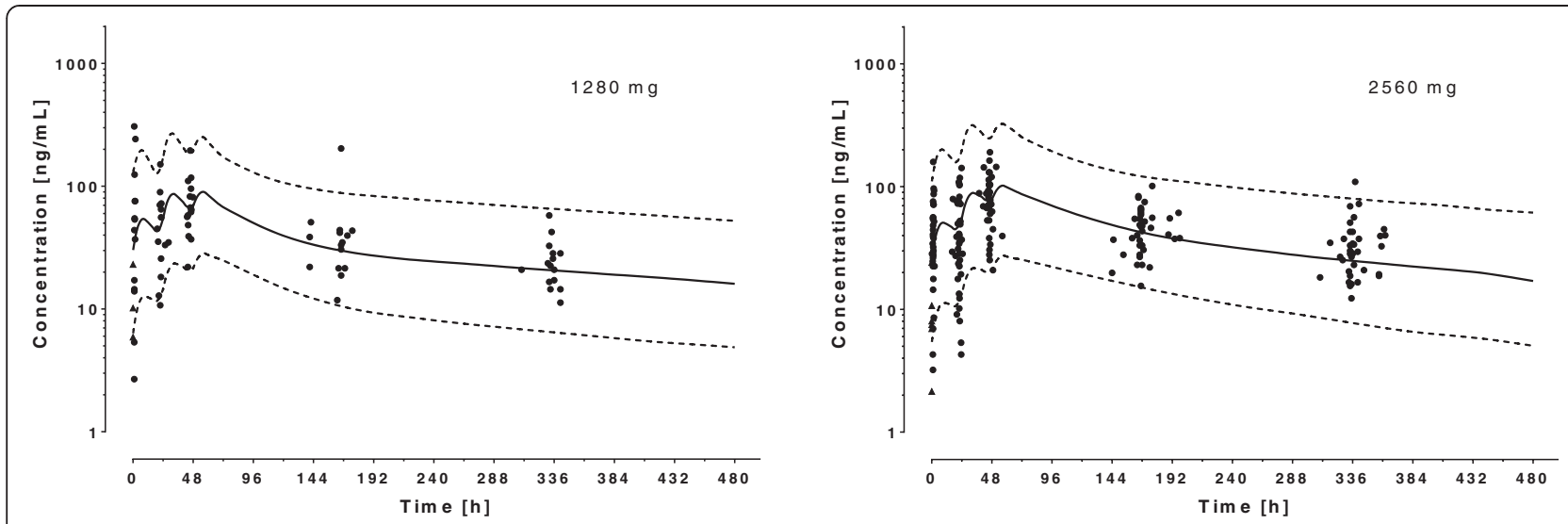

Figure 6 Observed piperaquine plasma concentrations after administration of $2 \times 480+320=1280 \mathrm{mg}$ (children) and $2 \times 960+640=$ $2560 \mathrm{mg}$ (adults) dose in 60 Cambodian patients. The solid lines represent the mean population prediction the dotted lines the $95 \%$ prediction intervals. Triangles represent residual plasma concentrations of mefloquine or piperaquine found prior treatment initiation.

Phnom Dék and 68.9\% in Cambodia Pramoy). Residual doses were low in Tanzania for LF, but much higher values were estimated in Cambodia for $\mathrm{MQ}$ and $\mathrm{PPQ}$, with up to approximately one quarter of an initial dose already present at baseline. The levels reflect the different residence times of these drugs; the proportions show the extent of unregulated drug use and selective pressure going on in these countries $[29,30]$.

\section{Determinants of exposure - implications for dosing}

There was a clear correlation between $C L, V_{C}$ and body weight for all drugs, which accounted for about $10-30 \%$ of the inter-individual variability in these two parameters. Body weight was highly correlated with age, sex and height and remained the only significant parameter in the multivariate analyses. This result supports the use of antimalarial dosing regimens based on body weight, or age as a proxy for it. What the model cannot predict is whether an additional correction to dosing should be made for children (or naïve adults) on account of lack of immunity.

The scaling factor of 0.75 for $C L$ and 1 for $V_{C}$ described the relationships with body weight adequately, with the exception of LF for which the usual allometric scaling function provided a worse description of the data. Although a controversy persists regarding the body weight-dependent allometric exponent in the literature, it is not clear whether a different scaling between children and adults should be expected for this specific drug, or whether some confounding factors (different compliance between adult and children, different food intake) could have contributed to this finding.

\section{Interactions and metabolism}

Most of the anti-malarial drugs are metabolized by CYPs and concomitant treatment with inhibitors or inducers of these enzymes might, therefore, influence their elimination. This study detected only an influence of CYP2C9 and CYP3A4 inhibitors on AM clearance, which was decreased by $70 \%$ in patients with concomitant treatment. The fact that very few co-medications were reported might explain the lack of interactions for LF, MQ or PPQ. For the latter, the metabolizing pathways are not known. Among other factors, genetic polymorphisms in the enzymes responsible for antimalarial drugs could represent another important source of variability. A population genetic- and pharmacokineticbased analysis was conducted to address this issue and published elsewhere [27].

\section{Other conditions potentially influencing exposure}

Pregnancy is known to lower blood concentrations of AM and LF, thus putting pregnant women at risk of underdosing [31]. This study enrolled only three pregnant women in Tanzania, which prevented estimating the influence of pregnancy on LF or AM drug levels.

Food intake has been shown to affect strongly the bioavailability of LF, MQ and PPQ [56-59]. In practice, this is a source of systematic under-dosing; in a study of the adherence to treatment regimens in Tanzania, only $0.4 \%$ of patients were reported to take their antimalarials with food [60]. While in the present study patients admitted to the health facility were provided with food, outpatients were advised to eat directly before or after supervised drug-intake but adherence to this recommendation was based on selfreporting only, which, against the background of the above-mentioned adherence study, made it unreliable to have food effect included in the analysis. The absence of food information represents, however, a clear limitation of this study. 

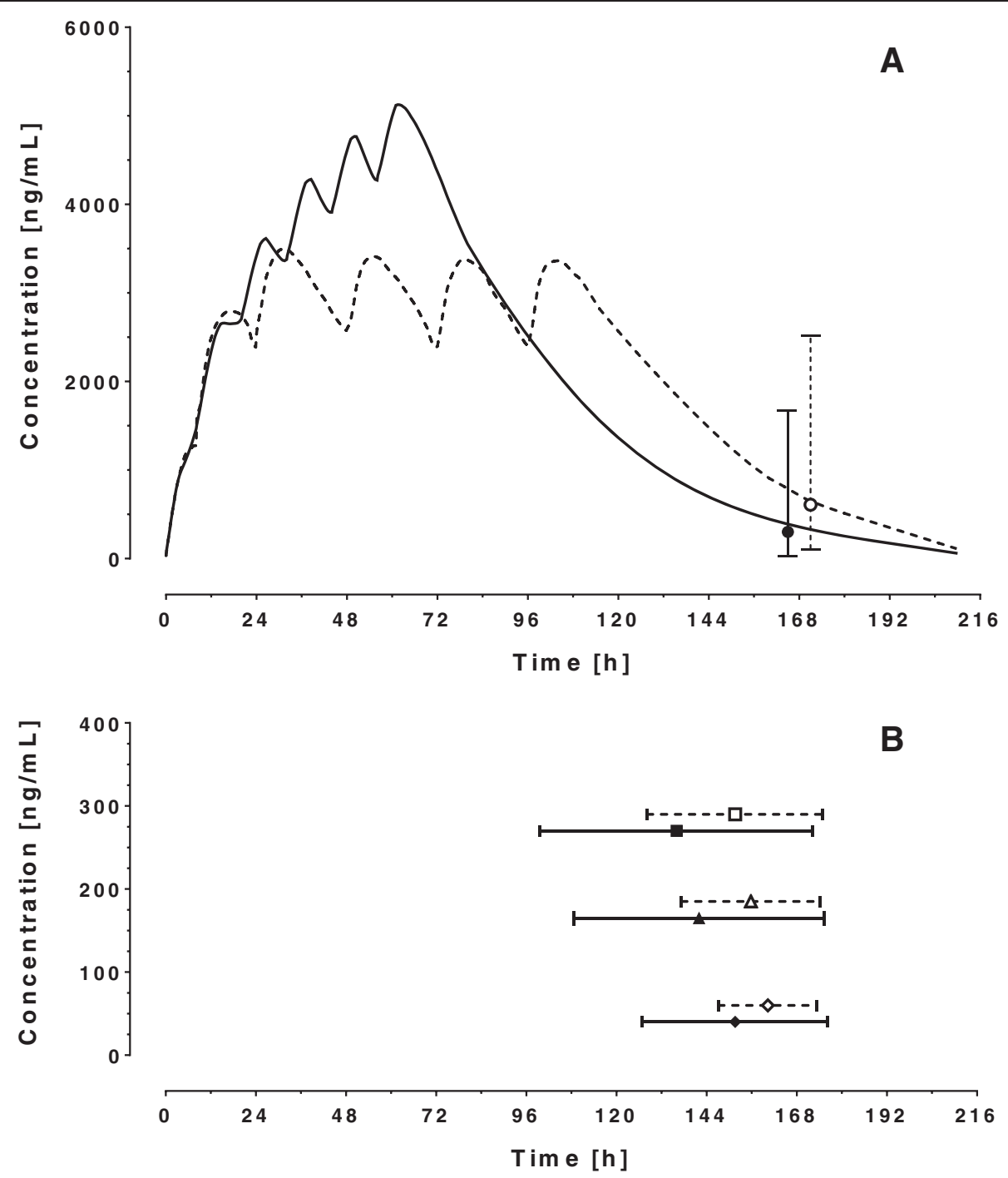

Figure 7 Concentration-time simulations of lumefantrine. A: Predicted median concentration of lumefantrine after administration of $6 \times$ $480 \mathrm{mg}$ (adults) regimen over 3 (continuous line) and 5 days (dotted line). Day 7 (168 h) median predicted concentrations (circles) with their $95 \%$ prediction intervals are shown for the two dosage regimens. B: Predicted mean ( $95 \%$ C.I.) time (estimated from time of last dose to $168 \mathrm{~h}$ ) at which concentrations lie below the cut-off values of $50 \mathrm{ng} / \mathrm{ml}$ (rhombi), $175 \mathrm{ng} / \mathrm{ml}$ (triangles) and $280 \mathrm{ng} / \mathrm{ml}$ (squares). Full and empty symbols associated with continuous and dotted lines represent 6-dose regimens over 3 and 5 days respectively.

\section{Structural and variance model}

These drugs are known to exhibit multi-compartmental pharmacokinetics (two- or three-compartment disposition model) that could not be well captured owing to the limited duration of sampling compared to other studies. Although our data could provide a good estimation of $C L$ and variability, appropriate description of terminal elimination phase could not be done. In addition, due to the very sparse sampling design during the absorption phase, no estimation of different absorption model could be performed, neither could the variability in the absorption quantified for LF, MQ and PPQ, with the exception of AM that exhibited a large inter-patient variability in its absorption. This large variability could result from both inherent characteristics of the drug $[46,61]$, and practical issues with dosing using crushed AM-LF pills (the paediatric formulation was not available for this study) [62]. Another limitation of this study is that no estimation could be made for AS and DHA for the AS-MQ and DHA-PPQ treatments.

\section{Simulations for LF}

While the notion of concentration-effect relationship for LF is generally accepted, there is yet no common understanding of what the therapeutic target concentration should be. The published day 7 LF concentrations associated with therapeutic response range from $175 \mathrm{ng} / \mathrm{ml}$

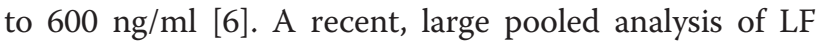


Table 5 Population estimate of clearance $(C L)$ and steady-state volume of distribution $\left(V_{s s}\right)$ of antimalarials for a person with a median body weight of $\mathbf{7 0} \mathbf{~ k g}$ from mixed effects models from the present study and in previous studies

\begin{tabular}{|c|c|c|c|c|c|c|c|}
\hline Drug & Subjects & Median age (range) [years] & No. of patients & Duration of sampling & $C L[\mathrm{~L} / \mathrm{h}]$ & $V_{s s}[\mathrm{~L}]$ & Ref. \\
\hline \multirow[t]{5}{*}{$\mathrm{AM}$} & Patients & $10(1-78)$ & 135 & 7 days & 598 & 129 & Present study \\
\hline & Patients & $22(14-60)$ & 217 & $360 \mathrm{~h}$ & $252^{a}$ & $304^{a}$ & {$[47]$} \\
\hline & Patients & $4.0(1-10)$ & 50 & $72 \mathrm{~h}$ & $182-700^{b}$ & 364 & {$[46]$} \\
\hline & Patients & $7.7 \pm 1.4^{c}$ & 13 & 28 days & 102 & 1263 & [48] \\
\hline & Pregnant women & $21(16-35)$ & 21 & $10 \mathrm{~h}$ & $1054^{d}$ & $2602^{d}$ & [49] \\
\hline \multirow[t]{3}{*}{$\mathrm{DHA}^{\mathrm{e}}$} & Patients & $10(1-78)$ & 135 & 7 days & 419 & $129^{f}$ & Present study \\
\hline & Patients & $22(14-60)$ & 217 & $360 \mathrm{~h}$ & $237^{a}$ & $147^{a}$ & {$[47]$} \\
\hline & Pregnant women & $21(16-35)$ & 21 & $10 \mathrm{~h}$ & 564 & 69 & [49] \\
\hline \multirow[t]{7}{*}{$\mathrm{LF}$} & Patients & $9(1-78)$ & 143 & 7 days & 7.7 & $265^{f}$ & Present study \\
\hline & Patients & $22(14-60)$ & 217 & - & 21 & 301 & {$[47]$} \\
\hline & Patients & $23(13-59)$ & 102 & - & 7 & 298 & [32] \\
\hline & Patients & $20(5-66)$ & 309 & - & 7.6 & 361 & [32] \\
\hline & Pregnant women & $24(15-42)$ & 103 & $336 \mathrm{~h}$ & 8.7 & 257 & [50] \\
\hline & Patients & $4.0(1-10)$ & 50 & $72 \mathrm{~h}$ & 5.4 & 623 & {$[46]$} \\
\hline & Patients & $7.7 \pm 1.4^{c}$ & 13 & 28 days & 7.29 & 506 & {$[48]$} \\
\hline \multirow[t]{2}{*}{$\mathrm{DLF}^{9}$} & Patients & $9(1-78)$ & 143 & 7 days & 336 & $265^{f}$ & Present study \\
\hline & Patients & $7.7 \pm 1.4^{c}$ & 13 & 28 days & 701 & $119^{\prime} 500$ & {$[48]$} \\
\hline \multirow[t]{5}{*}{$\mathrm{MQ}$} & Patients & $18(2-57)$ & 63 & 14 days & 2.4 & 625 & Present study \\
\hline & Patients & $14.8(8-61)$ & 128 & 28 days & 1.4 & 574.7 & [8] \\
\hline & Patients & $9.3(4-15)$ & 74 & 28 days & 3.71 & $1,089.2$ & [8] \\
\hline & Prophylaxis & $26^{h}(18-55)$ & 1,111 & 26 weeks & 1.75 & 863 & [51] \\
\hline & Patients & $19(2-55)$ & 50 & 63 days & 2.1 & 767.62 & [52] \\
\hline \multirow[t]{5}{*}{ PPQ } & Patients & $18(7-53)$ & 60 & 14 days & 109 & 42,820 & Present study \\
\hline & Patients & $3-55$ & 98 & 63 days & $98^{h}$ & $61,180^{i}$ & [53] \\
\hline & Patients & $6(2-10)$ & 236 & 42 days & 29 & 14,972 & [54] \\
\hline & Pregnant women & $25(18-43)$ & 24 & 84 days & 90 & 37,030 & [55] \\
\hline & Non-pregnant women & $27.5(18-45)$ & 24 & 84 days & 92 & 58,030 & {$[55]$} \\
\hline
\end{tabular}

Abbreviations: AM artemether, AS artesunate, DBL desbutyl-lumefantrine, DHA dihydroartemisinin, LF lumefantrine, MQ mefloquine, PPQ piperaquine.

${ }^{a}$ Fixed parameter at mean value.

${ }^{\mathrm{b}}$ From first to sixth dose.

c Mean \pm standard deviation.

${ }^{d}$ Parameter estimates are weight normalized based on published population mean values divided by the mean weight of subjects.

e Only as metabolite after administration of AM.

${ }^{f}$ Fixed to Vss of AM.

g Only as metabolite after administration of LF.

${ }^{\mathrm{h}}$ Mean.

i Population estimate for a patient with a median body weight of $48 \mathrm{~kg}$.

concentration-efficacy data confirmed that a strong association exists between low day 7 LF concentrations and an increased risk of recurrence until day 42 , and until day 21 for new infection [7]. However, the authors of the pooled analysis concluded that there is no clear cut-off value for the thresholds associated with risk of recrudescence or new infection, but that cut-offs can be defined based on achieving a proportion of the desirable effect. For example, in low transmission areas a cut-off of $125 \mathrm{ng} / \mathrm{ml}$ gave efficacy rates of $84 \%$ and $96 \%$ at 42 days, and in high transmission areas a cut-off of $50 \mathrm{ng} / \mathrm{ml}$ gave efficacy rates of $80 \%$ and $95 \%$ at 42 days. In the Tanzanian sample of this study, $35 \%$ of the patients had a concentration below the cut-off value of $175 \mathrm{ng} / \mathrm{ml}$, but only one of the 7 patients who had recurrent parasitaemia (unadjusted failure rate) was in this group.

Owing to the important variability in LF pharmacokinetics, the simulations under the standard 6-dose over 3 days schedule shows that a substantial proportion of the patients would present concentrations below the various proposed therapeutic targets at day 7 . The considerable inter-individual variability in LF plasma concentrations additionally suggests that in some patients plasma LF concentrations would fall below the proposed minimal concentrations between the fourth and seventh day $\left(3^{\text {rd }}\right.$ and $4^{\text {th }}$ cycles) after treatment (i.e. before all the 
parasite had been eradicated). Splitting the same recommended total dose over 5 days would greatly reduce the probability of exhibiting sub-therapeutic drug concentrations, as already shown by other studies $[32,63]$. However, in practice, the potential increased exposure with this 5 -day regimen may be impeded by the possible risk of lower adherence to the treatment. Very little evidence exists for the other compounds. For MQ, the time over the MIC seems an important component associated with treatment efficacy [8]. Our results indicate that this drug exhibits the least variability in its disposition and it is thus not expected that differences in response would be strongly related to variable drug levels.

\section{Additional file}

\section{Additional file 1: Number of samples per time point. The table} provided summarizes the number of patient samples included in the population pharmacokinetic model of each anti-malarial drug (and its metabolite where applicable) for every sampling time point.

\section{Abbreviations}

$\triangle \mathrm{OFV}$ : Difference in the minimum objective function value; $\theta$ : Typical value of given parameter in the population; ACT: Artemisinin-based combination therapy; AM: Artemether; AQ: Amodiaquine; AS: Artesunate; C.I.95\%: 95\% confidence interval; $C L$ : Systemic clearance; $C L_{\text {met }}$ : Metabolite clearance; CYP: Cytochrom P450 isoenzyme; DHA: Dihydroartemisinin; DLF: Debutyllumefantrine; $F_{0}$ : Residual amount of drug from the previous treatment; IIV: Inter-individual variability; $k_{22}$ : Metabolism rate constant from drug compartment to metabolite compartment; $k_{\mathrm{a}}$ : Absorption rate constant; LF: Lumefantrine; MIC: Minimal inhibitory concentration; MQ: Mefloquine; P.: Plasmodium; P.I. $95 \%$ : 95\% prediction interval; PN: Pyronaridine; PPQ: Piperaquine; PSN: Perl-speaks-NONMEM; Q: Inter-compartmental clearance; S.E.: Standard error; SP: Sulfadoxine-pyrimethamine; $V_{C}$ : Central volume of distribution; $V_{M}$ : Volume of distribution of the metabolites; $V_{p}$ : Peripheral volume of distribution; VPC: Visual predictive check; $V_{\text {Ss: }}$ Steady-state volume of distribution; WHO: World Health Organization; WWARN: World-Wide Antimalarial Resistance Network; $X$ : Covariate.

\section{Competing interests}

Support for this work was provided by grant No 320000-112479 from the Swiss National Science Foundation. The authors declare that they have no competing interests.

\section{Authors' contributions}

EMSH contributed to the design of the study, the acquisition of patient samples and laboratory data, the analysis and interpretation of data and to drafting of the manuscript. DS and AMK made substantial contributions to the acquisition of patient samples and the coordination of the study. FA was involved in the acquisition of patient samples and the assay development for the pharmacogenetic analysis. BZ, TM and LAD where involved in the assay development and in the quantitation of the drug concentration levels. MG and CC carried out the population pharmacokinetic analysis and made substantial contributions to interpretation of data and to drafting and revising the manuscript. TB contributed to interpretation of pharmacokinetic data and the revising of the manuscript. BG, HPB and PO conceived the study, participated in its design and coordination, helped to draft the manuscript and revised it critically for important intellectual content. All authors have given final approval of the version to be published.

\section{Authors' information}

The opinions expressed in this paper are those of the authors and may not reflect those of their employing organizations. PO is a staff member of the WHO; the authors alone are responsible for the views expressed in this publication and they do not necessarily represent the decisions, policy or views of the $\mathrm{WHO}$

\section{Acknowledgements}

The authors would like to thank the patients who participated in the study. Furthermore, the authors would like to thank the staff from the National Center for Parasitology, Entomology and Malaria Control in Cambodia, namely Dr. Leang Rithea, Dr. Mey Bouth Denis, Dr. Chivv Lim, Va Soch, and Oung Chavvin, the staff from Phnom Dék and Pramoy Health Centre in Cambodia, the staff from the Ifakara Health Institute in Tanzania, namely Dr. Hassan Mshinda, Aggrey Malila and Fidelis Mbena, the staff of the Kibanoi Health Centre in Tanzania and all the drivers for their help in the sample collection. The computations were performed at the Vital-IT (http://www. vital-it.ch) Center for high-performance computing of the Swiss Institute of Bioinformatics and the authors are grateful for their support.

\section{Author details}

${ }^{1}$ Swiss Tropical and Public Health Institute, University of Basel, Basel, Switzerland. ${ }^{2}$ School of Pharmaceutical Sciences, University of Geneva, University of Lausanne, Geneva, Switzerland. ${ }^{3}$ Division of Clinical Pharmacology and Toxicology, Department of Laboratories, Centre Hospitalier Universitaire Vaudois and University of Lausanne, Lausanne, Switzerland. ${ }^{4}$ National Center for Parasitology, Entomology and Malaria Control, Phnom Penh, Cambodia. Ifakara Health Institute, Dar es Salaam, Tanzania. ${ }^{6}$ Institut Pasteur in Cambodia, Molecular Epidemiology UnitInstitut Pasteur in Cambodia, Molecular Epidemiology Unit, Phnom Penh, Cambodia. ${ }^{7}$ UNICEF/UNDP/World Bank/WHO Special Programme for Research and Training in Tropical Diseases (TDR), Geneva, Switzerland. ${ }^{8}$ Department of Ambulatory Care and Community Medicine \& Division of Infectious Diseases, University Hospital, Lausanne, Switzerland.

Received: 12 March 2013 Accepted: 28 June 2013

Published: 10 July 2013

\section{References}

1. WHO: Guidelines for the treatment of malaria. Secondth edition. Geneva: World Health Organization; 2010.

2. WHO: World Malaria Report 2011. Geneva: World Health Organization; 2011.

3. Terlouw DJ, Nahlen BL, Courval JM, Kariuki SK, Rosenberg OS, Oloo AJ, Kolczak MS, Hawley WA, Lal AA, Kuile FO: Sulfadoxine-pyrimethamine in treatment of malaria in Western Kenya: increasing resistance and underdosing. Antimicrob Agents Chemother 2003, 47:2929-2932.

4. Barnes Kl, Watkins WM, White NJ: Antimalarial dosing regimens and drug resistance. Trends Parasitol 2008, 24:127-134.

5. Barnes KI, Little F, Smith PJ, Evans A, Watkins WM, White NJ: Sulfadoxinepyrimethamine pharmacokinetics in malaria: Pediatric dosing implications. Clin Pharmacol Ther 2006, 80:582-596.

6. WHO: Methods and techniques for assessing exposure to antimalarial drugs in clinical field studies. Geneva: World Health Organization; 2011.

7. Stepniewska K, Workman L, Aweeka F, Borrmann S, Faucher J-F, Genton B, Lindegardh N, Martensson A, Mayxay M, Nosten F, Piola P, Ringwald P, White NJ, Barnes K: Defining adequate lumefantrine exposure in patients with uncomplicated malaria treated with artemether-lumefantrine. In Poster LB-2212, presented at the $60^{\text {th }}$ American Society of Tropical Medicine and Hygiene (ASTMH) Annual Meeting 3-8 December 2011, Philadelphia, PA, USA.; 2011.

8. Simpson JA, Price R, ter Kuile F, Teja-Isavatharm P, Nosten F, Chongsuphajaisiddhi T, Looareesuwan S, Aarons L, White NJ: Population pharmacokinetics of mefloquine in patients with acute falciparum malaria. Clin Pharmacol Ther 1999, 66:472-484.

9. Barnes Kl, Lindegardh N, Ogundahunsi O, Olliaro P, Plowe CV, Randrianarivelojosia M, Gbotosho GO, Watkins WM, Sibley $\mathrm{CH}$, White $\mathrm{NJ}$ : World antimalarial resistance network (WARN) IV: Clinical pharmacology. Malar J 2007, 6:122.

10. Sevene E, Gonzalez R, Menendez C: Current knowledge and challenges of antimalarial drugs for treatment and prevention in pregnancy. Expert Opin Pharmacother 2010, 11:1277-1293.

11. White NJ, Stepniewska K, Barnes K, Price RN, Simpson J: Simplified antimalarial therapeutic monitoring: using the day-7 drug level? Trends Parasitol 2008, 24:159-163. 
12. Watkins WM, Mosobo M: Treatment of Plasmodium falciparum malaria with pyrimethamine-sulfadoxine: selective pressure for resistance is a function of long elimination half-life. Trans R Soc Trop Med Hyg 1993 , 87:75-78.

13. Denis MB, Tsuyuoka R, Lim P, Lindegardh N, Yi P, Top SN, Socheat D, Fandeur T, Annerberg A, Christophel EM, Ringwald P: Efficacy of artemether-lumefantrine for the treatment of uncomplicated falciparum malaria in northwest Cambodia. Trop Med Int Health 2006, 11:1800-1807.

14. Kabanywanyi AM, Mwita A, Sumari D, Mandike R, Mugittu K, Abdulla S: Efficacy and safety of artemisinin-based antimalarial in the treatment of uncomplicated malaria in children in southern Tanzania. Malar J 2007 6:146.

15. Antimalarial drug resistance, Thai-Cambodian border. Wkly Epidemiol Rec 2009, 84:94-95.

16. Resistance to artemisinin derivatives along the Thai-Cambodian border. Wkly Epidemiol Rec 2007, 82:360.

17. Dondorp AM, Nosten F, Yi P, Das D, Phyo AP, Tarning J, Lwin KM, Ariey F, Hanpithakpong W, Lee SJ, Ringwald P, Silamut K, Imwong M, Chotivanich K, Lim P, Herdman T, An SS, Yeung S, Singhasivanon P, Day NP, Lindegardh N, Socheat $D$, White $\mathrm{NJ}$ : Artemisinin resistance in Plasmodium falciparum malaria. N Engl J Med 2009, 361:455-467.

18. Burki T: Artemisinin resistance could endanger fight against malaria. Lancet Infect Dis 2009, 9:213.

19. Enserink M: Malaria. Signs of drug resistance rattle experts, trigger bold plan. Science 2008, 322:1776.

20. Duffy PE, Sibley H: Are we losing artemisinin combination therapy already? Lancet 2005, 366:1908-1909.

21. Maude RJ, Pontavornpinyo W, Saralamba S, Aguas R, Yeung S, Dondorp AM, Day NPJ, White NJ, White LJ: The last man standing is the most resistant: eliminating artemisinin-resistant malaria in Cambodia. Malar J 2009, 8:31.

22. Noedl H, Se Y, Schaecher K, Smith BL, Socheat D, Fukuda MM, Artemisinin Resistance in Cambodia 1 (ARC1) Study Consortium: Evidence of artemisinin-resistant malaria in Western Cambodia. N Engl J Med 2008, 359:2619-2620.

23. Samarasekera U: Countries race to contain resistance to key antimalarial. Lancet 2009, 374:277-280.

24. WHO: Drug resistance could set back malaria control success. World Health Organization; 2009. http://www.who.int/mediacentre/news/releases/2009/ malaria_drug resistance 20090225/en/.

25. Hodel EM, Zanolari B, Mercier T, Biollaz J, Keiser J, Olliaro P, Genton B, Decosterd LA: A single LC-tandem mass spectrometry method for the simultaneous determination of 14 antimalarial drugs and their metabolites in human plasma. J Chromatogr B Analyt Technol Biomed Life Sci 2009, 877:867-886.

26. Hodel EM, Ley SD, Qi W, Ariey F, Genton B, Beck HP: A microarray-based system for the simultaneous analysis of single nucleotide polymorphisms in human genes involved in the metabolism of antimalarial drugs. Malar J 2009, 8:285.

27. Staehli Hodel EM, Csajka C, Ariey F, Guidi M, Kabanywanyi AM, Duong S, Decosterd LA, Olliaro P, Beck HP, Genton B: Effect of Single Nucleotide Polymorphisms in Cytochrome P450 Isoenzyme and N-Acetyltransferase 2 Genes on the Metabolism of Artemisinin-Based Combination Therapies in Malaria Patients from Cambodia and Tanzania. Antimicrob Agents Chemother 2013, 57:950-958.

28. Beal SL, Sheiner LB, Boeckmann AJ (Eds): NONMEM Users Guides (1989-2006). Ellicott City, Maryland, USA: Icon Development Solutions; 2006.

29. Hodel EM, Genton B, Zanolari B, Mercier T, Duong S, Beck HP, Olliaro P, Decosterd LA, Ariey F: Residual antimalarial concentrations before treatment in patients with malaria from Cambodia: indication of drug pressure. J Infect Dis 2010, 202:1088-1094.

30. Hodel EM, Kabanywanyi AM, Malila A, Zanolari B, Mercier T, Beck HP, Buclin T, Olliaro P, Decosterd LA, Genton B: Residual antimalarials in malaria patients from Tanzania-implications on drug efficacy assessment and spread of parasite resistance. PLoS One 2009, 4:e8184.

31. Tarning J, Bergqvist $Y$, Day NP, Bergquist J, Arvidsson B, White NJ, Ashton M, Lindegardh N: Characterization of human urinary metabolites of the antimalarial piperaquine. Drug Metab Dispos 2006, 34:2011-2019.

32. White NJ, van Vugt M, Ezzet F: Clinical pharmacokinetics and pharmacodynamics of artemether-lumefantrine. Clin Pharmacokinet 1999, 37:105-125.
33. Navaratnam V, Mansor SM, Sit NW, Grace J, Li QG, Olliaro P: Pharmacokinetics of artemisinin-type compounds. Clin Pharmacokinet 2000, 39:255-270.

34. Novartis Pharma Corporation: Coartem. Full prescribing information 2009.

35. Khoo S, Back D, Winstanley P: The potential for interactions between antimalarial and antiretroviral drugs. AIDS 2005, 19:995-1005.

36. Ilett KF, Ethell BT, Maggs JL, Davis TME, Batty KT, Burchell B, Binh TQ, Thu LTA, Hung NC, Pirmohamed M, Park BK, Edwards G: Glucuronidation of dihydroartemisinin in vivo and by human liver microsomes and expressed UDP-glucuronosyltransferases. Drug Metab Dispos 2002, 30:1005-1012.

37. Fontaine F, de Sousa G, Burcham PC, Duchene P, Rahmani R: Role of cytochrome P450 3A in the metabolism of mefloquine in human and animal hepatocytes. Life Sci 2000, 66:2193-2212.

38. Ridtitid W, Wongnawa M, Mahatthanatrakul W, Chaipol P, Sunbhanich M: Effect of rifampin on plasma concentrations of mefloquine in healthy volunteers. J Pharm Pharmacol 2000, 52:1265-1269.

39. Ridtitid W, Wongnawa M, Mahatthanatrakul W, Raungsri N, Sunbhanich M: Ketoconazole increases plasma concentrations of antimalarial mefloquine in healthy human volunteers. J Clin Pharm Ther 2005, 30:285-290.

40. van Agtmael MA, van der Graaf CAA, Dien TK, Koopmans RP, van Boxtel CJ: The contribution of the enzymes CYP2D6 and CYP2C19 in the demethylation of artemether in healthy subjects. Eur J Drug Metab Pharmacokinet 1998, 23:429-436.

41. Anderson BJ, Holford NHG: Mechanism-based concepts of size and maturity in pharmacokinetics. Annu Rev Pharmacol Toxicol 2008, 48:303-332.

42. Lindbom L, Pihlgren P, Jonsson EN: PsN-Toolkit-a collection of computer intensive statistical methods for non-linear mixed effect modeling using NONMEM. [Erratum appears in Comput Methods Programs Biomed. 2005 Dec;80(3):277 Note: Jonsson, Niclas [corrected to Jonsson, E Niclas]]. Comput Methods Programs Biomed 2005, 79:241-257.

43. Lindbom L, Ribbing J, Jonsson EN: Perl-speaks-NONMEM (PsN)-a Perl module for NONMEM related programming. Comput Methods Programs Biomed 2004, 75:85-94.

44. Perl-speaks-NONMEM (PsN). http://psn.sourceforge.net/.

45. GraphPad Software. http://www.graphpad.com

46. Hietala SF, Martensson A, Ngasala B, Dahlstrom S, Lindegardh N, Premji Z, Farnert A, Gil P, Bjorkman A, Ashton M: Population pharmacokinetics and pharmacodynamics of artemether and lumefantrine during combination treatment in children with uncomplicated falciparum malaria in Tanzania. Antimicrob Agents Chemother 2010, 54:4780-4788.

47. Ezzet F, Mull R, Karbwang J: Population pharmacokinetics and therapeutic response of CGP56697 (artemether plus benflumetol) in malaria patients. Br J Clin Pharmacol 1998, 46:553-561.

48. Salman S, Page-Sharp M, Griffin S, Kose K, Siba PM, llett KF, Mueller I, Davis TM: Population pharmacokinetics of artemether, lumefantrine, and their respective metabolites in Papua New Guinean children with uncomplicated malaria. Antimicrob Agents Chemother 2011, 55:5306-5313.

49. Tarning J, Kloprogge F, Piola P, Dhorda M, Muwanga S, Turyakira E, Nuengchamnong N, Nosten F, Day NP, White NJ, Guerin PJ, Lindegardh N: Population pharmacokinetics of artemether and dihydroartemisinin in pregnant women with uncomplicated Plasmodium falciparum malaria in Uganda. Malar J 2012, 11:293.

50. Tarning J, McGready R, Lindegardh N, Ashley EA, Pimanpanarak M, Kamanikom B, Annerberg A, Day NPJ, Stepniewska K, Singhasivanon P, White NJ, Nosten F: Population pharmacokinetics of lumefantrine in pregnant women treated with artemether-lumefantrine for uncomplicated Plasmodium falciparum malaria. Antimicrob Agents Chemother 2009, 53:3837-3846.

51. Charles BG, Blomgren A, Nasveld PE, Kitchener SJ, Jensen A, Gregory RM, Robertson B, Harris IE, Reid MP, Edstein MD: Population pharmacokinetics of mefloquine in military personnel for prophylaxis against malaria infection during field deployment. Eur J Clin Pharmacol 2007, 63:271-278.

52. Ashley EA, Stepniewska K, Lindegardh N, McGready R, Hutagalung R, Hae R, Singhasivanon P, White NJ, Nosten F: Population pharmacokinetic assessment of a new regimen of mefloquine used in combination treatment of uncomplicated falciparum malaria. Antimicrob Agents Chemother 2006, 50:2281-2285.

53. Tarning J, Ashley EA, Lindegardh N, Stepniewska K, Phaiphun L, Day NPJ, McGready R, Ashton M, Nosten F, White NJ: Population pharmacokinetics of piperaquine after two different treatment regimens with 
dihydroartemisinin-piperaquine in patients with Plasmodium falciparum malaria in Thailand. Antimicrob Agents Chemother 2008, 52:1052-1061.

54. Tarning J, Zongo I, Some FA, Rouamba N, Parikh S, Rosenthal PJ, Hanpithakpong W, Jongrak N, Day NP, White NJ, Nosten F, Ouedraogo JB, Lindegardh N: Population pharmacokinetics and pharmacodynamics of piperaquine in children with uncomplicated falciparum malaria. Clin Pharmacol Ther 2012, 91:497-505.

55. Tarning J, Rijken MJ, McGready R, Phyo AP, Hanpithakpong W, Day NP White NJ, Nosten F, Lindegardh N: Population pharmacokinetics of dihydroartemisinin and piperaquine in pregnant and nonpregnant women with uncomplicated malaria. Antimicrob Agents Chemother 2012, 56:1997-2007.

56. Crevoisier C, Handschin J, Barre J, Roumenov D, Kleinbloesem C: Food increases the bioavailability of mefloquine. Eur J Clin Pharmacol 1997, 53:135-139.

57. Hoffmann-La Roche Ltd: Lariam. Full prescribing information 2009.

58. Price RN, Uhlemann AC, van Vugt M, Brockman A, Hutagalung R, Nair S, Nash D, Singhasivanon P, Anderson TJC, Krishna S, White NJ, Nosten F: Molecular and pharmacological determinants of the therapeutic response to artemether-lumefantrine in multidrug-resistant Plasmodium falciparum malaria. Clin Infect Dis 2006, 42:1570-1577.

59. Sim IK, Davis TME, llett KF: Effects of a high-fat meal on the relative oral bioavailability of piperaquine. Antimicrob Agents Chemother 2005, 49:2407-2411.

60. Kabanywanyi AM, Lengeler C, Kasim P, King'eng'ena S, Schlienger R, Mulure $\mathrm{N}$, Genton B: Adherence to and acceptability of artemether-lumefantrine as first-line anti-malarial treatment: evidence from a rural community in Tanzania. Malar J 2010, 9:48.

61. Ali S, Najmi MH, Tarning J, Lindegardh N: Pharmacokinetics of artemether and dihydroartemisinin in healthy Pakistani male volunteers treated with artemether-lumefantrine. Malar J 2010, 9:275.

62. Abdulla S, Sagara I, Borrmann S, D'Alessandro U, Gonzalez R, Hamel M, Ogutu B, Martensson A, Lyimo J, Maiga H, Sasi P, Nahum A, Bassat Q, Juma E, Otieno L, Björkman A, Beck HP, Andriano K, Cousin M, Lefèvre G, Ubben D, Premji Z: Efficacy and safety of artemether-lumefantrine dispersible tablets compared with crushed commercial tablets in African infants and children with uncomplicated malaria: a randomised, single-blind, multicentre trial. Lancet 2008, 372:1819-1827.

63. Ezzet F, van Vugt M, Nosten F, Looareesuwan S, White NJ: Pharmacokinetics and pharmacodynamics of lumefantrine (benflumetol) in acute falciparum malaria. Antimicrob Agents Chemother 2000, 44:697-704.

doi:10.1186/1475-2875-12-235

Cite this article as: Staehli Hodel et al:: Population pharmacokinetics of mefloquine, piperaquine and artemether-lumefantrine in Cambodian and Tanzanian malaria patients. Malaria Journal 2013 12:235.

\section{Submit your next manuscript to BioMed Central and take full advantage of:}

- Convenient online submission

- Thorough peer review

- No space constraints or color figure charges

- Immediate publication on acceptance

- Inclusion in PubMed, CAS, Scopus and Google Scholar

- Research which is freely available for redistribution 